THE EFFECTS OF GOVERNMENT SPONSORED ENTERPRISE (GSE) STATUS ON THE PRICING OF BONDS ISSUED BY THE FEDERAL FARM CREDIT BANKS FUNDING CORPORATION (FFCB)

\author{
A Dissertation \\ Presented to the Faculty of the Graduate School \\ of Cornell University \\ In Partial Fulfillment of the Requirements for the Degree of \\ Master of Science
}

by

Yiwo Wang

August 2011 
(C) 2011 Yiwo Wang 


\title{
THE EFFECTS OF GOVERNMENT SPONSORED ENTERPRISE (GSE) STATUS ON THE PRICING OF BONDS ISSUED BY THE FEDERAL FARM CREDIT BANKS FUNDING CORPORATION (FFCB)
}

\author{
Yiwo Wang, M.S. \\ Cornell University, 2011
}

This thesis develops a framework to price the implicit government guarantee embedded in the bonds issued by the Farm Credit System. It shows that the value of the implicit government guarantee for a specific bond is dependent on the yield spread, the risk-free interest rate, the maturity and the future value of the bond price. It also reconfirms Merton's theory (1974) that yield spreads are influenced by variances of the firm (volatility square), maturity and quasi debt to collateral value ratio (d-ratio). Furthermore, the hypothetical bond yields for the Farm Credit System bonds without GSE status are calculated based on the Black-Scholes Model. 


\section{BIOGRAPHICAL SKETCH}

The author was born in Xi'an, China. She grew up in Xi'an and moved to Germany at the age of 16. She finished her high school in Gaienhofen, which was a small town located on the German-Swiss border. After that, she studied Economics at the University of Munich and got her B.S. degree in August 2008. She got her M.A. degree in Economics at the University of Munich in August 2009. In order to gain more international experience and knowing the leading role of the USA in financial markets, she came to Cornell University in August 2009 to study Applied Economics and Management. Her interests in financial markets were further strengthened by her internships at UBS Hong Kong and China Investment Corporation. 
Dedicated to My Parents 


\section{ACKNOWLEDGMENTS}

First of all, I want to take this opportunity to thank the chair of my committee Professor Calum Turvey. His advice, encouragement and stimulating suggestions accompanied me to finish this thesis. It would have been impossible for me to finish this thesis without his help. I also want to thank my minor Professor Edith Liu, whose inspiring suggestions helped me to get deeper insight into my work and improve my model.

I also want to express my gratitude and thanks to David Just and Linda Morehouse for all the things they have done for me.

My parents Jun Wang and Yan Fang helped me to find the courage to overcome all challenges I encountered during my graduate program. I want to thank my AEM fellow graduate students Stephanie Chan, Xiaolin Cui, Jie Li, Yu Qin, Yidi Xia and Zhen Xu for their friendship during my stay at Cornell. 


\section{TABLE OF CONTENTS}

\section{CHAPTER 1}

1.1

1.2

1.3

1.4

CHAPTER 2

CHAPTER 3

3.1

3.2

3.3

3.4

CHAPTER 4

CHAPTER 5

5.1

5.2

5.3

5.4

5.5

5.6

5.7

\section{FARM CREDIT SYSTEM}

Introduction

1

Overview

Business Model

Structure and Ownership

LITERATURE REVIEW

8

MODEL

Basic Idea

10

The Impact of GSE status

15

Risk

20

Coupon Payments

DATA

RESULT

Risk-free Interest rate and bond yield

41

Put and Spread

44

Put Price

49

Implied volatility

54

Spread and Volatility

57

Hypothetical Farm Credit System bond yield without

GSE status

69

Sensitivity analysis

73

5.7.1 Various volatilities

73

5.7.2 Various d-ratios

74 


\section{LIST OF FIGURES}

Figure 1 Participators of the Farm Credit System 3

Figure 2 Ownership of the Farm Credit System 5

Figure 3 Compositions of the Farm Credit System’s assets in $2010 \quad 11$

Figure 4 Relationship between collateral, liabilities and equity 14

Figure 5 Coupon payments and implied volatilities $\quad 29$

Figure 6 Short-term Farm Credit System bond yields 34

Figure 7 Medium-term and long-term Farm Credit System bond yields 35

Figure 8 Spread between short-term treasury yields and FCS yields 36

Figure 9 Spread between medium-term treasury yields and FCS yields 39

Figure 10 Spread between long-term treasury yields and FCS yields 40

Figure 11 Relationship between risk-free interest rate and bond yield 43

Figure 12 Relationship between put price and yield spread $\quad 47$

Figure 13 Put price and spread adjusted to the same scale 48

Figure 14 Regression results for linear regression model for put price 52

Figure 15 Correlation matrix for treasury yields 53

Figure 16 Correlation matrix for spreads $\quad 53$

Figure 17 Calculation of the implied volatilities $\quad 54$

Figure 18 Average and median implied volatilities for different maturities 56

Figure 19 Relationship between volatilities and spread 66

Figure 20 Impact of variance of the firm and quasi debt to collateral value ratio on the yield spread (Source: Merton(1974)) 58

Figure 21 Quasi debt to collateral value ratios over the observation period 67

$\begin{array}{ll}\text { Figure } 22 \text { Comparison with Merton’s result } & 68\end{array}$

Figure 23 Impact of maturity on yield spread (Source: Merton(1974)) 61

Figure 24 Relationship between maturity and spread for a given volatility and a

close-to-constant d-ratio

63

Figure 25 Impact of d-ratios on yield and comparison with Merton's finding

(Source: Merton (1974)) 


\section{LIST OF TABLES}

Table 1 Summary statistics for the Farm Credit System bond yields 34

Table 2 Summary statistics for spreads 36

Table 3 R-square values for a linear regression model for put price 50

Table 4 Summary statistics for implied volatilities of different maturities 55

Table 5 Maxima and Minima of the d-ratios for all maturities 59

Table 6 Relationship between spread and maturity for a given volatility

and a close-to-constant d-ratio $\quad 62$

Table 7 Relationship between spread and maturity for a given volatility

but various d-ratios $\quad 63$

Table 8 Average quasi debt to collateral value ratios, average implied

$\begin{array}{ll}\text { volatilities and average spreads for all maturities. } & 64\end{array}$

Table 9 95\% confidence interval of the historical land price volatility 69

Table 10 Hypothetical yields without GSE status under constant

$\begin{array}{ll}\text { volatility }(6.07 \%) & 70\end{array}$

Table 11 Hypothetical yields without GSE status under adjusted

$\begin{array}{ll}\text { volatilities } & 71\end{array}$

Table 12 Impact of various volatilities on yields 73

Table 13 Impact of various d-ratios on yields $\quad 75$

Table 14 Average d-ratios for 3M bonds with different net collateral

$\begin{array}{ll}\text { ratios } & 76\end{array}$ 


\section{LIST OF ABBREVIATIONS}

Farm Credit System FCS

Federal Farm Credit Banks Funding Corporation FFCB

Government Sponsored Enterprise GSE 


\section{Chapter 1}

\section{Farm Credit System}

\subsection{Introduction}

The current financial crisis which was originally caused by the sub-prime crisis in 2007 has long escalated to a global financial economic crisis. The failure of two government sponsored enterprises (GSE) Fannie Mae and Freddie Mac has cost the US government billions of dollars. According to a report, “On Oct 21, 2010 FHFA estimates revealed that the bailout of Freddie Mac and Fannie Mae will likely cost taxpayers \$224-360 billion in total, with over $\$ 150$ billion already provided”1

Since then, there has been a debate on the benefits and costs of GSE status. While many people think that the benefits of the GSEs to the economy are very significant, many other people think that the potential costs of the GSEs are so high that their GSE status should be removed.

As one of the several GSEs, the Farm Credit System is in danger of losing its GSE status. One immediate question would be: what would be the impact on the Farm Credit System if it lost its GSE status?

This thesis is devoted to answering this question.

\footnotetext{
${ }^{1}$ Davidson, Paul "Fannie, Freddie bailout to cost taxpayers \$154 billion". 2010-10-22 , USA Today 


\subsection{Overview}

The Farm Credit System (FCS) is a government sponsored enterprise (GSE) established in 1916 by the U.S. Congress. Its mission is "to provide sound and dependable credit to American farmers, ranchers, producers or harvesters of aquatic products, their cooperatives and certain farm-related businesses”2. The system consists of three parts: the Farm Credit System Associations (Associations), the Farm Credit System Banks (Banks) and the Farm Credit System Funding Cooperation (FFCB). A USDA Economic Research released at the end of 2008 shows that approximately 39 percent of the real estate and non-real estate credit needs of U.S. agriculture were met by System institutions ${ }^{3}$.

As of December 31, 2010, the FCS had 5 Banks (Ag First Farm Credit Bank, AgriBank, Farm Credit Bank of Texas, U.S. AgBank and CoBank) and 84 Associations throughout the nation. Unlike commercial banks, the 5 Banks and the 84 Associations do not take deposits, "the Banks obtain a substantial majority of funds for their lending operations through the issuance of Systemwide Debt Securities, but also obtain some of their funds from internally generated earnings, from the issuance of common and preferred equities and from the issuance of subordinated debt” ${ }^{4}$.

\footnotetext{
${ }^{2}$ Please refer to P. 5 of the annual report 2010 released by FFCB.

${ }^{3} \mathrm{http} / / /$ www.farmcredit-ffcb.com/farmcredit/fcsystem/overview.jsp

${ }^{4}$ Please refer to P.7 of the annual report 2010 released by FFCB.
} 


\subsection{Business Model}

Figure 1 depicts how the Farm Credit System works ${ }^{5}$.

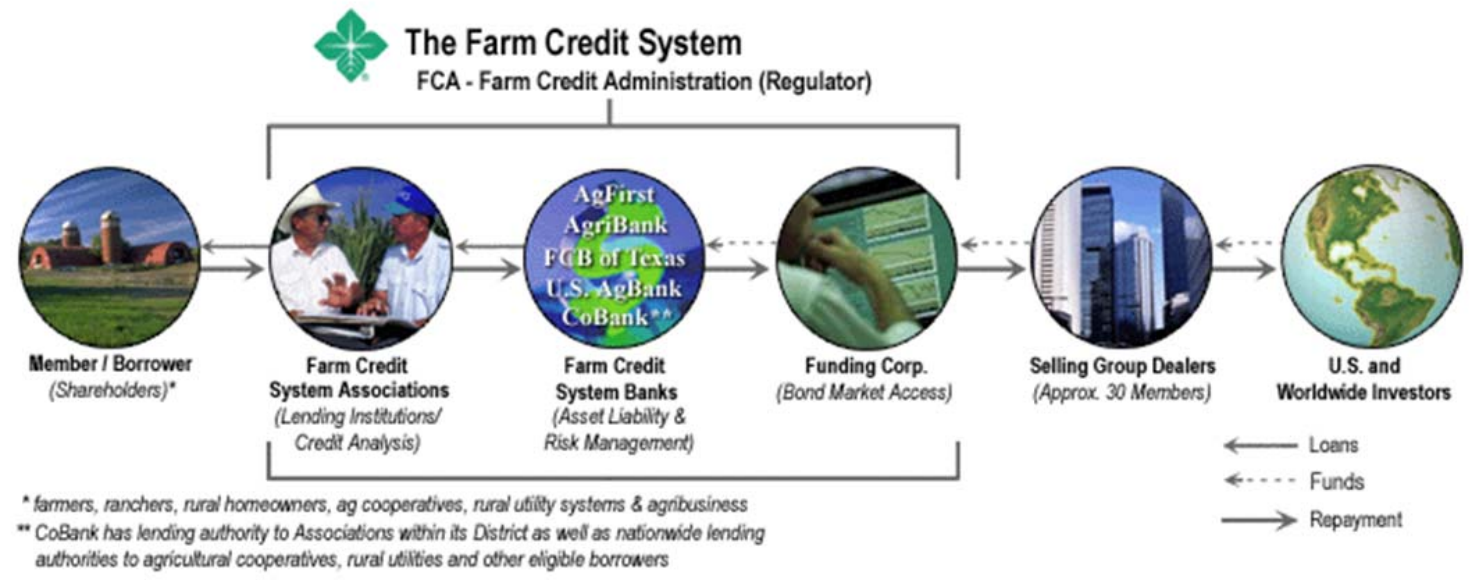

Figure 1 Participators of the Farm Credit System

The Banks can participate in the issuance of Systemwide Debt Securities (Farm Credit System bonds) to raise money. The Federal Farm Credit Bank Funding Coopertaion issues bonds on a daily basis to meet the needs of the Banks. The Farm Credit System bonds will be sold in the capital market through a selling group dealers. As of December $31^{\text {st }} 2010$, there were 30 members in this group. The primary holders of the FCS bonds are “commercial banks, states, municipalities, pension and money-market funds, insurance companies, investment companies, corporations and foreign banks and govenments” ${ }^{6}$ all over the world. Funds raised by the bond issuance will be given to the Banks. The Banks will make wholesale loans to the Associations. The Associations will offer loans to farmers.

\footnotetext{
${ }^{5}$ http://www.farmcredit-ffcb.com/farmcredit/fcsystem/overview.jsp

${ }^{6}$ Please refer to P.11 of the annual report 2010 released by FFCB
} 
Regarding the repayments of the bonds: The farmers will pay their loans back to the Associations. This money will be used by the Associations to repay their wholesale loans to the Banks. The Banks will pay the Federal Farm Credit Funding Corporation, who will use this money to pay the coupons and the principals of the bonds to the investors through the selling group dealers. 


\subsection{Structure and Ownership}

The ownership of the Farm Credit System is depicted in Figure $\mathbf{2}^{7}$.

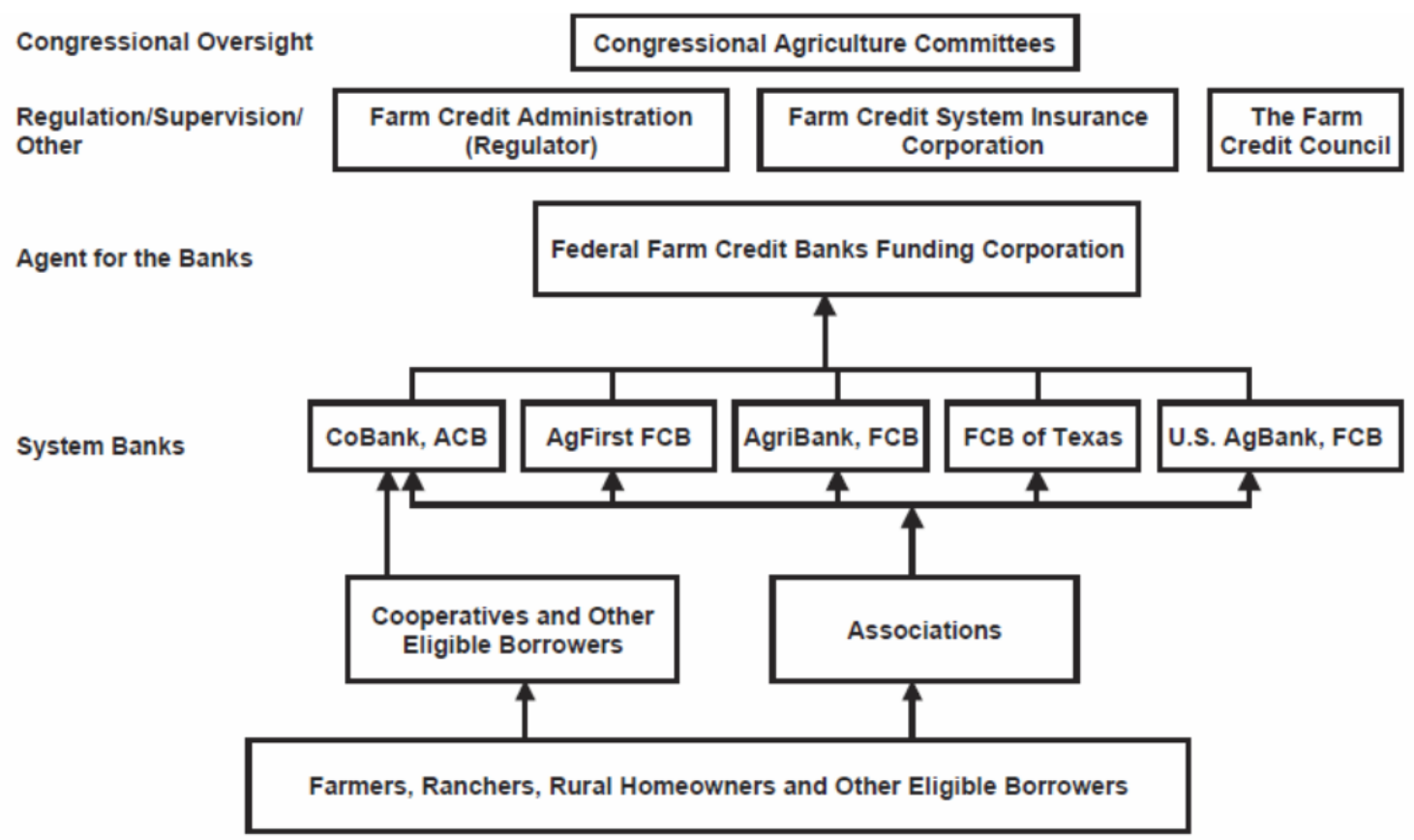

Figure 2 Ownership of the Farm Credit System

The 84 Associations are owned by their borrowers including farmers, ranchers, rural homeowners and other eligible borrowers. The 5 Banks are primarily owned by their affiliated Associations. Unlike the other 4 Banks which are wholly owned by their affiliated Associations, the CoBank is owned by cooperatives, other eligible borrowers and the affiliated Associations. The 5 Banks own the Federal Farm Credit Banks Funding Corporation jointly.

\footnotetext{
${ }^{7}$ Please refer to P.5 of the annual report 2010 released by FFCB
} 
The Farm Credit Administration is the regulator of the Farm Credit System who supervises the whole system. The Farm Credit Administration is a federal agency.

The Farm Credit System Insurance Corporation is an independent U.S. Governmentcontrolled corporation, which was founded in the late 1980s. It provides additional protections to the Farm Credit System by insuring, "to the extent that funds are available, the timely payment of principal and interest on the Farm Credit Debt Securities”。.

The Farm Credit Council is "a federated trade association representing the System before Congress, the Executive Branch and others"9.

The Farm Credit System is dependent on its GSE status and has benefited a lot from its implicit government guarantee. However, it is in danger of losing its GSE status due to the current financial crisis. The purpose of this thesis is to investigate the impact that the loss of GSE status might have on the pricing of the Farm Credit System bonds and the bond yield that the Farm Credit System can offer its rural and cooperative customers. In order to achieve this purpose, specific objectives are

a. To provide an overview of Farm Credit System bond pricing relative to treasuries

b. To determine the market price of risk for Farm Credit System bonds

c. To determine the benefit of the implicit government guarantee

d. To assess the consequences of loss of GSE status.

More technically, this thesis investigates

\footnotetext{
${ }^{8}$ http://www.farmcredit-ffcb.com/farmcredit/fcsystem/overview.jsp

${ }^{9}$ Please refer to P.12 of the annual report 2010 released by FFCB
} 
e. Why could GSE status be interpreted as a implicit European put option and how is the put option price determined?

f. What are the factors influencing the yield spreads?

g. What are the hypothetical yields for the Farm Credit System bonds with different maturities without GSE status?

While some research which has been done earlier considered GSE status and the implicit government guarantee of the Farm Credit System, none has advanced to the point of quantitative assessment.

This thesis is primarily based on the Black-Scholes-Model, Merton's paper "On the Pricing of Corporate Debt: The Risk Structure of Interest Rates” published in 1974 and Gray, Merton and Bodie’s paper “Contingent Claims Approach to Measuring and Managing Sovereign Credit Risk” published in 2007. Viewing the Farm Credit System bonds problem through the lens of option pricing is an original contribution of this thesis.

The thesis is organized as follows. In the first chapter the overview, the business model and the structure and the ownership of the Farm Credit System are presented. A literature review can be found in the second section, which summarizes the previous research related to GSE status of the Farm Credit System. The third chapter demonstrates the model. Chapter four is used to describe the data. Results are presented in the fifth section. Chapter six concludes. 


\section{Chapter 2}

\section{Literature Review}

Not much research has been done on the Farm Credit System bonds. Previous research primarily focuses on the structure of the FCS and the justifications of GSE status. Most of them use qualitative arguments rather than quantitative arguments.

Lins and Barry (1984) summarize the previous research focusing on the question if and how GSE status should be removed. They present the pros and cons of GSE status and discuss the economic impact of different ways of removing GSE status. The alternative includes (a) abrupt removal of part or all of the regulatory exemptions and preferences, (b) phased removal of selected exemptions and preferences, (c) phased removal by limiting the amount of agency securities issued, and (d) an increasing fee schedule for the privilege of agency status until the agency involved voluntarily drops the status. However, they are unable to decide which alternative is better and conclude that the magnitudes of the impact of these alternatives are still disputed.

Freshwater (1997) assesses the pros and contras of the Farm Credit System as a GSE. He argues that since the agricultural sector has become less important and the capital market has become more efficient, GSE status is not as necessary as it used to be. Still, despite the rapid development of the capital market, it is not perfect. A clearly defined focus and the expansion of the FCS's business to nonagricultural credit needs could justify its GSE status.

Jensen (2000) uses a supply and demand model and an options model to show that the existing competitive market is enough to meet the credit needs and GSE status does not 
seem to be justified. Moreover, the implicit guarantee enables the borrowers to transfer risks to taxpayers, which leads to deadweight losses.

Lee and Irwin (1996) focus on the restructuring process of the FCS since its establishment in 1916. The FCS tried to reduce the number of Banks and Associations to reduce costs and achieve higher efficiency. However, there is no proof that the restructuring led to a better financial performance.

In one of the only qualitative assessment on the Farm Credit System, Tauer and Weersink (1988) discuss the optimal risk-premium of the FCS based on a dynamic optimization model and show how to minimize the cost of a member borrowing. They find that as the equity of the FCS increases, the perceived risk of bond holders falls and the associated risk premium required by investors declines.

In conclusion, little research has been done to quantify the impact of GSE status on the cost of raising capital, which is the primary focus of this thesis. Previous research on the FCS could be used as complements to this thesis. They address many other issues which are not covered in this thesis. 


\section{Chatper3}

\section{Model}

\subsection{Basic Idea}

As described in chapter 1.3, the Banks get fund through bond issuances. According to the annual report 2010 released by the Federal Farm Credit Bank Funding Cooperation (FFCB), Farm Credit Administration regulations require the Banks to maintain a net collateral ratio of at least $103 \%{ }^{10}$. The "net collateral ratio" is defined as "net collateral (primarily earning assets) divided by total liabilities less subordinated debt, subject to certain limits”

Since the Farm Credit System does not disclose the net collateral ratio applied for every single bond issuance, outsiders do not know the exact net collateral ratio for a given bond. Therefore, it is reasonable for outsiders to assume that the Banks maintain a net collateral ratio of $103 \%$ for all bond issuances.

The two most important assets of the Farm Credit System are net loans and cash, federal funds sold and investments. The ratios of net loans and cash, federal funds sold and investment to the total assets have remained stable over the years. The total assets of the Farm Credit System in 2010 are displayed in Figure 3.

\footnotetext{
${ }^{10}$ Please refer to FFCB annual report 2010 page 17 “Bank Collateral Requirements” section

${ }^{11}$ Please refer to FFCB annual report 2010 page 44 "Structural Risk Management “ section
} 


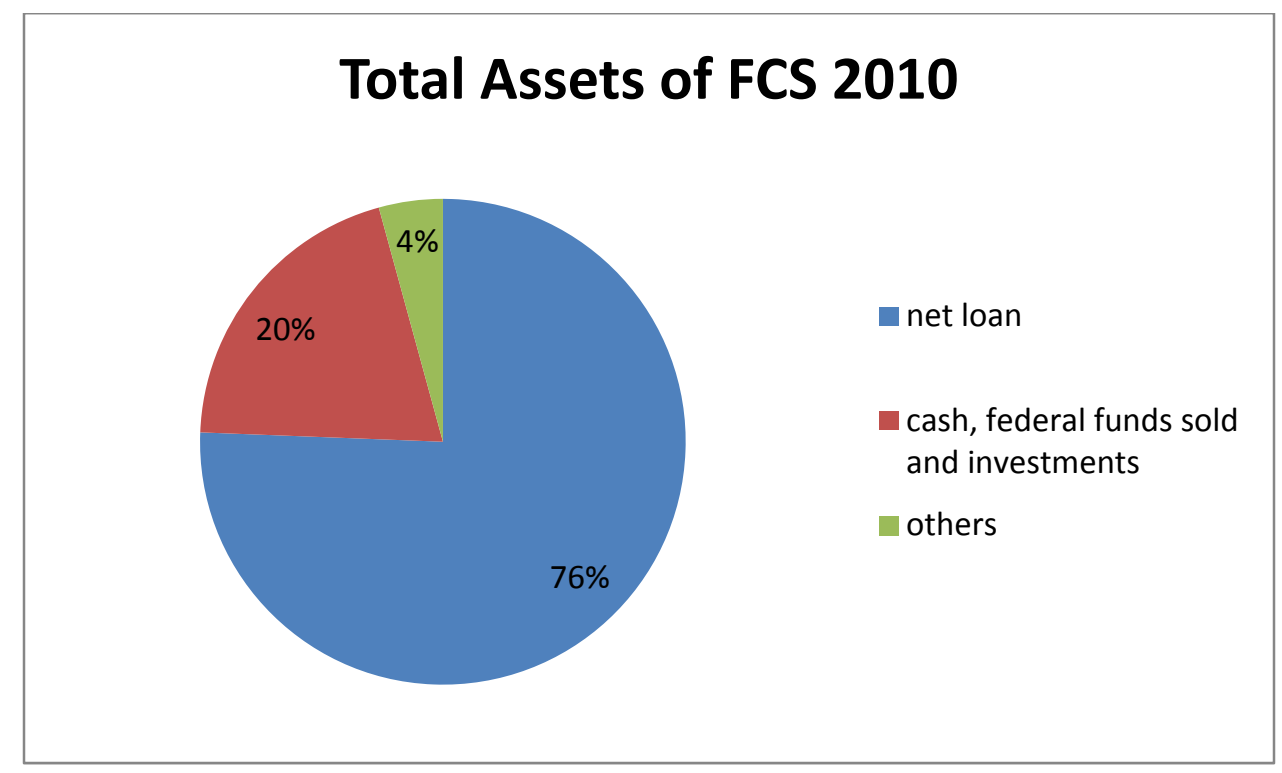

Figure 3 Compositions of the Farm Credit System's assets in 2010

Moreover, subordinated debt was $0.84 \%$ of the total liabilities in both 2010 and 2009, $0.56 \%$ of the total liabilities in 2008 and $0.31 \%$ of the total liabilities in $2007^{12}$, which was so small that could be ignored in the calculation. Therefore, the first relationship which could be derived from the FFCB Annual Report 2010 is:

$$
A(0)=1.03 L(0)(1)
$$

with $\boldsymbol{A}(\mathbf{0})$ representing the collateral value at the time of bond issuance and $\boldsymbol{L}(\mathbf{0})$ representing the liabilities at the time of the bond issuance.

The liabilities of the Farm Credit System at the time of the bond issuance are the money received from the bond issuance. For a zero-coupon bond with the face value $\boldsymbol{B}$, yield-tomaturity $\boldsymbol{y}$ and maturity $\boldsymbol{T}$, the liabilities at time $\mathbf{0}$ are defined as

\footnotetext{
12 Please refer to FFCB annual report 2010 page 3
} 


$$
L(0)=B e^{-y T} .
$$

It will be shown in chapter 3.4 that coupon payments will not influence the results. Therefore, coupon payments will be ignored in this chapter for simplicity's sake.

A bond with the face value $\boldsymbol{B}$ has a present value of $\boldsymbol{B} \boldsymbol{e}^{-\boldsymbol{r} \boldsymbol{T}}$ at the time of the bond issuance, given the risk-free interest rate is $\boldsymbol{r}$. However, if the yield-to-maturity $\boldsymbol{y}$ and the risk-free interest rate $\boldsymbol{r}$ are different, the market value of the bond (liabilities at time $\mathbf{0}$ ) has less value than the present value of the face value $\left(\boldsymbol{B} \boldsymbol{e}^{-\boldsymbol{r} \boldsymbol{T}}\right)$ because of the risks attached to the bond. The difference between a risk-free bond and a risky bond is a bond guarantee, which guarantees the repayment of the face value $\boldsymbol{B}$ in case of default:

\section{$\mathbf{L}(0)=$ Risk-free Bond - Bond Guarantee (2)}

The bond guarantee can also be interpreted as an implicit European put option $\boldsymbol{P ( 0 )}$ on the collateral with the strike price $\boldsymbol{K}$ and the same maturity as the bond.

The next step is to find the strike price $\boldsymbol{K}$, which can be derived from the definition of the bond guarantee. Since the implicit put allows the put holder to sell the collateral at the price of $\boldsymbol{K}$ at time $\boldsymbol{T}$ to cover the bond repayment, the strike price $\boldsymbol{K}$ must be equal to the liabilities of the Farm Credit System at time $\boldsymbol{T}$. For a bond without coupon payments, the liabilities at time $\boldsymbol{T}$ are the face value of the bond $\mathbf{B}$ :

$$
K=L(T)=B
$$

With a put option, equation (2) could be redefined as 


$$
L(\mathbf{0})=K e^{-r T}-P(\mathbf{0})
$$

The difference between the collateral value $\boldsymbol{A ( 0 )}$ and the liabilities $\mathbf{L}(\mathbf{0})$ is the excessive value of the collateral over the liabilities at time $\mathbf{0}$, which is nothing but the equity of the Farm Credit System at time $\mathbf{0}$. The equity allows the Farm Credit System to buy the collateral at the price of $\boldsymbol{B}$ at time $\boldsymbol{T}$ (Farm Credit System repays the bond on time and leaves the collateral untouched). Thus, equity is an implicit European call option $\boldsymbol{C}(\mathbf{0})$ on the collateral with the strike price $\boldsymbol{B}$ and the same maturity as the bond:

$$
\begin{aligned}
& \text { Collateral }=\text { Liabilities }+ \text { Equity } \\
& A(0)=K e^{-r T}-P(0)+C(0)(4)
\end{aligned}
$$

Moreover, it is interesting to notice that the above equation must always hold. The putcall parity is used to prove it. The put-call parity requires that the put option price must be equal to the present value of the strike price plus the call option price less the spot price of the underlying asset. Mathematically, it is

$$
P(\mathbf{0})=K e^{-r T}-A(0)+C(0)
$$

Using equation (4) and substitute the put option price with the put-call parity, it yields:

$$
\begin{gathered}
A(0)=K e^{-r T}-K e^{-r T}+A(0)-C(0)+C(0) \\
A(0)=A(0)
\end{gathered}
$$

The Figure 4 summarizes and visualizes the above findings: 

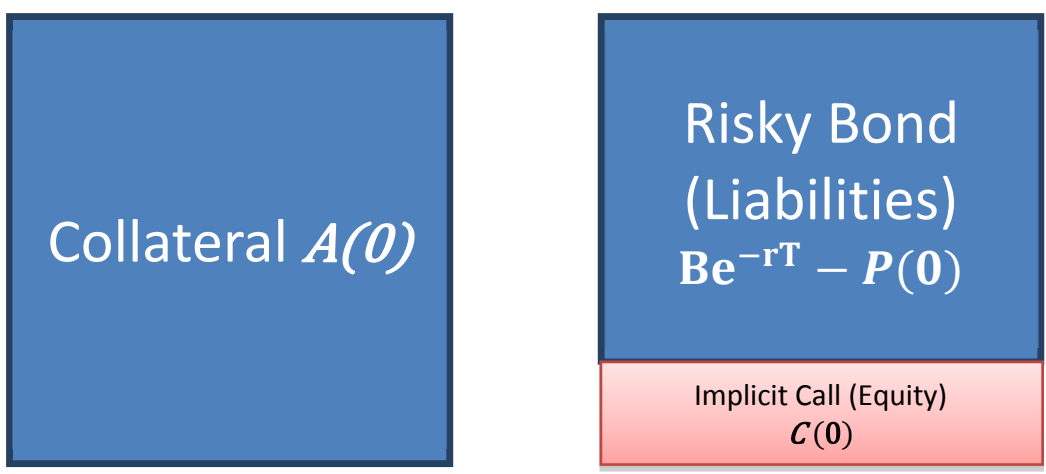

At the time of the bond issuance, the call option allows the call holder (Farm Credit

System) to buy the collateral with a strike price $\mathbf{B}$ at time $\mathbf{T}$, the Put option allows the put holder (Farm Credit System) to sell the collateral at the price of $\boldsymbol{B}$ at time $\boldsymbol{T}$. Since the Farm Credit Administration regulations require the net collateral ratio to be no less than 103\%, equity is positive at time $\mathbf{0}$.

Figure 4 Relationship between collateral, liabilities and equity 


\subsection{The Impact of GSE status}

Generally speaking, if there were no GSE status, the bond price $\boldsymbol{L}(\mathbf{0})$ with the face value $\boldsymbol{B}$, a promised coupon payment of $\boldsymbol{C}$ per period, a yield to maturity $\boldsymbol{y}^{\prime}$ ( $\boldsymbol{y}^{\prime}$ is used to represent the yield of a bond without GSE status) and maturity $\boldsymbol{T}$ would be

$$
L(0)=\sum_{t=1}^{T} C e^{-y^{\prime} t}+B e^{-y^{\prime} T}
$$

Since there are risks attached to a bond, investors expect a risk premium for the money they invest for that risky bond. A risk premium is the spread $\boldsymbol{s}^{\prime}$ ( $\boldsymbol{s}^{\prime}$ is used to represent the spread of the Farm Credit System bonds without GSE status) between the bond yield $\boldsymbol{y}^{\prime}$ and the risk-free interest rate $\boldsymbol{r}$.

$$
\boldsymbol{s}^{\prime}=\boldsymbol{y}^{\prime}-\boldsymbol{r}
$$

With respect to the risk-free interest rate: since the treausry bonds enjoy the explicit guarantee of the US government, the yields of the US treasury bonds will be used as riskfree interest rates $\boldsymbol{r}$.

If a given bond has a zero spread, it means that investors consider this bond to be riskfree. Investors expect positive spread for a risky bond, because they need to get compensation for the risk they are taking. With other words, the expected payments of the coupons $\boldsymbol{C}_{\boldsymbol{t}}$ and the face value $\boldsymbol{B}_{\boldsymbol{T}}$ are less than the stated amount of payments. For a risk-neutral investor, it is 


$$
\sum_{t=1}^{T} C e^{-y^{\prime} t}+B e^{-y^{\prime} T}=\sum_{t=1}^{T} C_{t} e^{-r t}+B_{T} e^{-r T}<\sum_{t=1}^{T} C e^{-r t}+B e^{-r T}
$$

At the time of the bond issuance, the expected coupon payments for all periods should be the same $\left(\boldsymbol{C}_{\mathbf{1}}=\boldsymbol{C}_{\mathbf{2}}=\cdots=\boldsymbol{C}_{\boldsymbol{T}}\right.$ ) because the expected underlying risks are the same.

For any period before the bond matures, the difference between the promised payment $\boldsymbol{C}$ and the expected payment $\boldsymbol{C}_{\boldsymbol{t}}$ could be interpreted as a put option, which is sold by the investor and bought by the bond issuer at time $\mathbf{0}$. The value of the put at the expiration date is

$$
P(t)=C-C_{t}(6)
$$

This put option allows the bond issuer to default on the coupon payment. In exchange for this right, the bond issuer pays the bond holder more money ( $\boldsymbol{C}$ instead of $\boldsymbol{C}_{\boldsymbol{t}}$ ) if he decides not to exercise the put option.

Since both $\boldsymbol{C}$ and $\boldsymbol{C}_{\boldsymbol{t}}$ will be the same for all periods, $\boldsymbol{P}(\boldsymbol{t})$ will stay the same for all periods $^{13}$.

The put price will change when the bond matures. At this time, not only the coupon but also the face value of the bond need to be paid. The value of the put $\boldsymbol{P}(\boldsymbol{T})$ at the expiration date is

$$
P(T)=C-C_{T}+B-B_{T}>P(t)(7)
$$

By substituting (6) and (7) in equation (5), it could be rearranged as

\footnotetext{
13 Time value of money is not considered at this point.
} 


$$
\begin{aligned}
\sum_{t=1}^{T-1}(C-P(t)) e^{-r t}+(B+C-P(T)) e^{-r T} \\
=\sum_{t=1}^{T} C e^{-r t}+B e^{-r T}-\sum_{t=1}^{T-1} P(t) e^{-r t}-P(T) e^{-r T}
\end{aligned}
$$

Therefore, the liabilities (bond price) for the bond issuer at the time of the bond issuance is the present value of all future cash flows minus a compounded put option consisting of $\boldsymbol{T}$ European put options ${ }^{14}$ with the expiration date on each scheduled payment date. For simplicity’s sake, the compounded option will be referred to as option $\boldsymbol{P ( 0 )}$

$$
P(0)=\sum_{t=1}^{T-1} P(t) e^{-r t}+P(T) e^{-r T}
$$

and

$$
L(0)=\sum_{t=1}^{T} C e^{-r t}+B e^{-r T}-\sum_{t=1}^{T-1} P(t) e^{-r t}+P(T) e^{-r T}=\sum_{t=1}^{T} C e^{-r t}+B e^{-r T}-P(0) .
$$

With the GSE status, the expected coupon payments and expected face value repayment will increase due to the implicit guarantee of the governement.

$$
C_{t}^{G S E}>C_{t} \text { and } B_{T}^{G S E}>B_{T}(\mathbf{8})
$$

By substituting equation (8) into equation (6) and (7), it yields

$$
P(t)^{G S E}=C-C_{t}^{G S E}<P(t)
$$

\footnotetext{
${ }^{14}$ This model is valid for bonds with annual coupon payment. This model could be easily adjusted to semiannual coupon payments ( $2 \boldsymbol{T}$ options instead of $\boldsymbol{T}$ options).
} 


$$
P(T)^{G S E}=C-C_{t}^{G S E}+B-B_{T}^{G S E}<P(T)
$$

Therefore, by holding everything else constant, the compounded put price with GSE status will be smaller than the compounded put price without GSE status.

$$
P(0)^{G S E}=\sum_{t=1}^{T-1} P(t)^{G S E} e^{-r t}+P(T)^{G S E} e^{-r T}<P(0)=\sum_{t=1}^{T-1} P(t) e^{-r t}+P(T) e^{-r T}
$$

The difference between the compounded put price without GSE status and the compounded put price with GSE status is the impact of the implicit government guarantee on the bond price.

Since the compounded put price with GSE status is smaller than the compounded put price without GSE status $\boldsymbol{P}(\mathbf{0}) \boldsymbol{G S E}<\boldsymbol{P}(\mathbf{0})$, the bond issued by the Farm Credit System with GSE status has a higher price $\boldsymbol{L}(\mathbf{0})^{\boldsymbol{G S} \boldsymbol{E}}>\boldsymbol{L}(\mathbf{0})$, the yield of the bond is lower $\boldsymbol{y}<$ $\boldsymbol{y}^{\prime}$. The Farm Credit System benefits from GSE status and the cost for captial is lower.

For Example, if investors expect that the the government will pay back all FCS's liabilities for sure in case of default, which means

$$
C_{t}^{G S E}=C \text { and } B_{T}^{G S E}=B
$$

It would indicate that

$$
\begin{gathered}
P(t)^{G S E}=C-C_{t}^{G S E}=0 \\
P(T)^{G S E}=C-C_{t}^{G S E}+B-B_{T}^{G S E}=0
\end{gathered}
$$


This means that the price for the compounded put price is zero.

$$
\boldsymbol{P}(\mathbf{0})=\mathbf{0}
$$

The bond price would be

$$
L(0)=\sum_{t=1}^{T} C e^{-r t}+B e^{-r T}-P(0)=\sum_{t=1}^{T} C e^{-r t}+B e^{-r T}
$$

This means, if investors expect that there is no risk attached to the bond, the bond price is the present value of all future cash flows.

However, since an implicit guarantee is not equivalent to an explicit guarantee, investors will not expect that $\boldsymbol{C}_{\boldsymbol{t}}^{\boldsymbol{G S E}}=\boldsymbol{C}$ and $\boldsymbol{B}_{\boldsymbol{T}}^{\boldsymbol{G S} \boldsymbol{E}}=\boldsymbol{B}$. Therefore, $\boldsymbol{P}(\mathbf{0})$ is bigger than $\mathbf{0}$ and the bond price is lower than the present value of all future cash flows. The Farm Credit System issuses bond at a rate which is higher than the risk-free interest rate $(\boldsymbol{y}>\boldsymbol{r})$. 


\subsection{Risk}

The Farm Credit System is not risk-free because the value of the collateral changes over time. The two most important compositions of the assets which are used as collateral for bonds are loans and investment. As shown in Figure 3, they account for $76 \%$ and $20 \%$ of the whole assets, respectively. The values of these two parts together determine if the Farm Credit System is able to repay the bond on time.

Regarding the loans on the asset side of the Farm Credit System: farmers get loans from the Associations; the Federal Farm Credit Banks Funding Corporation issues bonds to raise money for the farmers. As long as the collateral value does not fall below a certain barrier, farmers will pay back their loans. The Farm Credit System will have enough money to repay their bonds. The investors will get their money back from the Farm Credit System. However, if the collateral value falls below a certain barrier, it is better for the farmers to default on their loans. The Farm Credit System gets the collateral instead.

The loans of the Farm Credit system consist of different loan programs, of which only about half of them are the traditional agricultural loans which are collateralized by lands. However, since land prices are a good indicator for the overall performance of the agricultural business, historical land price volatility is used as a proxy for the volatility of the loans.

It is hard to estimate the market perception for the volatility of the investments, which account for $20 \%$ of the whole asset. Even though it is possible to calculate the annual 
change of the investments ${ }^{15}$ and derive the historical volatility of the investments, there is not enough information disclosed in the annual report which can be used to derive the correlation between the volatility of the loans and the volatility of the investments. Therefore, it is impossible to derive the overall volatility of the business of the Farm Credit System (the volatility of the collateral).

Since the main purpose of this paper is to demonstrate a mechanism which can be used to derive the yield spreads of the Farm Credit System bonds without GSE status, the market perception of the operation volatility of the Farm Credit System without GSE status is not the focus of this paper. Therefore, it is assumed that the historical land price volatility represents the volatility of the Farm Credit System's business. To make the model more robust, a sensitivity analysis with various volatilities is done to show the impact of different collateral volatilities.

If the Farm Credit System had no GSE status, it would have no choice but to default on the loan once they were in liquidity problem. The investors would not be able to get all of their money back. However, since the Farm Credit System has a GSE status, the market may expect that the government would help the Farm Credit System to repay the debt in difficult times. Therefore, the expected coupon payments and the expected principal repayment increase. In other words, the implicit guarantee changes investors' perception of the risk (volatility of land price) the Farm Credit System is exposed to.

To derive the market perception for the volatility of the FCS with GSE status, the put price needs to be calculated. It is shown earlier that

\footnotetext{
${ }^{15}$ Data are available from 1997 to 2010.
} 


$$
K e^{-y T}=K e^{-r T}-P(0) .
$$

Solving the above equation ${ }^{16}$, the yield of the risky debt is

$$
y=-\frac{1}{T} \ln \frac{K e^{-r T}-P(0)}{K}
$$

The spread $\boldsymbol{s}$ between the risk-free interest rate and the yield of the risky debt is ${ }^{17}$

$$
s=y-r=-\frac{1}{T} \ln \left(1-\frac{P(0)}{K e^{-r T}}\right)
$$

Rearrange the equation and solve for $\boldsymbol{P}(\mathbf{0})$, it yields

$$
P(0)=\left(1-e^{-s T}\right) K e^{-r T}(9)
$$

This equation shows a way to calculate the price of the implicit put option. The put option price only depends on the spread $\boldsymbol{s}$, the risk-free interest rate $\boldsymbol{r}$ and the maturity of the debt $\boldsymbol{T}$.

Since all these three variables are observable, the put price for a given bond at the time of the bond issuance $\boldsymbol{P}(\mathbf{0})$ can be calculated. Once the put price $\boldsymbol{P}(\mathbf{0})$ is calculated, this can be plugged into the Black-Scholes Model and used to derive the implied volatilities of the land price, which is market perception for the risk of the Farm Credit System business under GSE status.

\footnotetext{
${ }^{16}$ Detailed calculation see appendix 1 which can be found at the end of the section.

${ }^{17}$ Detailed calculation see appendix 2 which can be found at the end of the section.
} 


\section{Example}

On February $10^{\text {th }} 2011$, the $3 \mathrm{M}$ treasury yield $(\boldsymbol{r})$ was $0.12 \%$, the $3 \mathrm{M}$ bond yield issued by the Farm Credit System $(\boldsymbol{y})$ was $0.2168 \%$. The spread $(\boldsymbol{s})$ between the bond yield and the treasury yield was $0.0968 \%$. The maturity of the bond $(\boldsymbol{T})$ was 0.25 .

Plugging $\boldsymbol{r}, \boldsymbol{S}$ and $\boldsymbol{T}$ into equation (9) and taking $\boldsymbol{B}=\boldsymbol{K}=\mathbf{1 0 0}$, it yields the put option price at the time of the debt issuance $\boldsymbol{P}(\mathbf{0})$, which was $\$ 0.024$. The liabilities at time $\mathbf{0}$ were $\$ 99.94$ and the value of the equity (call) was $\$ 3.00$. The collateral required for this bond issuance was $\$ 102.94$.

This means, for a 3M bond with a face value of $\$ 100$ issued on February $10^{\text {th }} 2011$, the price for a put which guaranteed the repayment of \$100 in 3 months (face value of the bond) was $\$ 0.024$. The liabilities which were equal to the amount of money the Farm Credit System receives were $\$ 99.94$, the value of the call (equity) was $\$ 3.00$. The value of the liabilities and the value of the equity summed up to $\$ 102.94$, which was equal to the value of the collateral.

Plugging the put price $\boldsymbol{P}(\mathbf{0})$ (\$0.024), $\mathbf{A}(\mathbf{0})$ (\$102.94), K (\$100) and $\mathbf{r}(0.12 \%)$ into the Black-Scholes Model to derive the implied volatilities, which ensured that the put price calculated by the Black-Scholes model was equal to the implicit put option price $\boldsymbol{P}(\mathbf{0})$.

The implied volatility of the land price in this case was 3.27\%. This was the market expectation for the land price volatility the Farm Credit System with GSE status was bearing on February $10^{\text {th }}$ 2011. If the implied volatility of the land price were smaller 
than the actual volatility of the land price on this day, the Farm Credit System would benefit from GSE status. 


\subsection{Coupon Payments}

The above model totally ignores coupon payments during the life of a given bond. In this section, it is shown that coupon payments do not influence the results.

The amount of money received at the time of the bond issuance is the bond price $\boldsymbol{B P}(\mathbf{0})$ which is equal to the liabilities $\boldsymbol{L}(\mathbf{0})$. This is the market value of all coupon payments and the market value of the face value at time $\mathbf{0}$.

Mathematically, it is

$$
B P(0)=L(0)=\sum_{t=0}^{T} \text { coupon payment } e^{-y t}+(\text { Face Value }) e^{-y T}
$$

The value of all coupon payments as of time 0 is $\sum_{t=0}^{T} \operatorname{coupon}_{\text {payment }} \boldsymbol{e}^{-y t}$. The future value of all the coupon payments as of time $\boldsymbol{T}$ is

$$
e^{y T} \sum_{t=0}^{T} \text { coupon payment } e^{-y t}
$$

Therefore, the strike price $\boldsymbol{K}$ of the put option on a bond with coupon payments at time $\boldsymbol{T}$ is the sum of the face value and the future value of all coupon payments at time $\boldsymbol{T}$.

Mathematically, it is

$$
K=\text { Face Value }+e^{y T} \sum_{t=0}^{T} \text { coupon payment } e_{t}^{-y t}=e^{y T} L(0)(10)
$$


If the strike price $\boldsymbol{K}$ of a put option changes, the implicit put option price $\boldsymbol{P}(\mathbf{0})$ will change accordingly. The price of the implicit put option is shown in the previous chapter and it is

$$
P(0)=\left(1-e^{-s T}\right) K e^{-r T}
$$

The derivatives of the put price with respect to the strike price is

$$
\frac{d P(0)}{d K}=\left(1-e^{-s T}\right) e^{-r T}(1
$$

It is shown that the relationship between the put price and the strike price is linear if the spread and risk-free interest rate are given.

Moreover, it is assumed earlier that the ratio between the value of the collateral $\boldsymbol{A}(\mathbf{0})$ and the value of the liabilities $\mathrm{L}(\mathbf{0})$ at time $\mathbf{0}$ is always $103 \%$. Substituting this relationship into equation (10), it yields

$$
K=e^{y T} L(0)=e^{y T} \frac{1}{1.03} A(0)
$$

which can be rearranged to

$$
\frac{A(0)}{K}=1.03 e^{-y T}(12)
$$

It shows that the ratio between the collateral value and the strike price never changes.

According to the Black-Scholes Model, the put price is 


$$
P(0)=K e^{-r T} N\left(-d_{2}\right)-A(0) N\left(-d_{1}\right)
$$

Substituting equation (12) into equation (13), it yields

$$
P(0)=K\left(e^{-r T} N\left(-d_{2}\right)-1.03 e^{-y T} N\left(-d_{1}\right)\right)
$$

The formula for $\boldsymbol{d}_{\mathbf{1}}$ and $\boldsymbol{d}_{\mathbf{2}}$ are

$$
d_{1}=\frac{\ln \left(\frac{A(0)}{K}\right)+\left(r+\frac{\sigma^{2}}{2}\right) T}{\sigma \sqrt{T}}
$$

and

$$
d_{2}=\frac{\ln \left(\frac{A(0)}{K}\right)+\left(r-\frac{\sigma^{2}}{2}\right) T}{\sigma \sqrt{T}}
$$

Substituting (12) in $\boldsymbol{d}_{\mathbf{1}}$ and $\boldsymbol{d}_{\mathbf{2}}$, it yields

$$
d_{1}=\frac{\ln \left(1.03 e^{-y T}\right)+\left(r+\frac{\sigma^{2}}{2}\right) T}{\sigma \sqrt{T}}
$$

and

$$
d_{2}=\frac{\ln \left(1.03 e^{-y T}\right)+\left(r-\frac{\sigma^{2}}{2}\right) T}{\sigma \sqrt{T}}
$$

The derivatives of the put price to the strike price is 


$$
\begin{aligned}
& \frac{d P(0)}{d K}=e^{-r T} N\left(-d_{2}\right)-1.03 e^{-y T} N\left(-d_{1}\right) \\
& \quad-K\left(e^{-r T} N^{\prime}\left(-d_{2}\right) \frac{\partial d_{2}}{\partial K}-1.03 e^{-y T} N^{\prime}\left(-d_{1}\right) \frac{\partial d_{1}}{\partial K}\right)
\end{aligned}
$$

By equating equation (14) and equation (11), it yields

$$
\begin{gathered}
\left(1-e^{-s T}\right) e^{-r T}=e^{-r T} N\left(-d_{2}\right)-1.03 e^{-y T} N\left(-d_{1}\right)-K\left(e^{-r T} N^{\prime}\left(-d_{2}\right) \frac{\partial d_{2}}{\partial K}-\right. \\
\left.1.03 e^{-y T} N^{\prime}\left(-d_{1}\right) \frac{\partial d_{1}}{\partial K}\right)(15)
\end{gathered}
$$

If the risk-free interest rate $\boldsymbol{r}$, the spread $\boldsymbol{s}$ and the maturity $\boldsymbol{T}$ are given ${ }^{18}$, the term on the LHS of the equation is a constant and does not change with the strike price. If equation (15) needs to hold, it requires that $\boldsymbol{d}_{\mathbf{1}}$ and $\boldsymbol{d}_{\mathbf{2}}$ do not change, given a change of the strike price. This condition will ensure that the terms on the RHS of equation (15) is a constant, even though the strike price does not remain the same. As shown in the formula, $\boldsymbol{d}_{\mathbf{1}}$ and $\boldsymbol{d}_{\mathbf{2}}$ are dependent on the yield-to-maturity of the bond, the risk-free interest rate, the maturity and the variances of the collateral. Since the yield-to-maturity, the risk-free interest rate and the maturity are given, the only way to make $\boldsymbol{d}_{\mathbf{1}}$ and $\boldsymbol{d}_{\mathbf{2}}$ unchanged with a change of the strike price is to keep the implied volatility $\boldsymbol{\sigma}$ (and the variance of the collateral) unchanged with a change of the strike price $\boldsymbol{K}$.

Since the change of the strike price does not have an influence on the implied volatility $\boldsymbol{\sigma}$ (and the variance of the collateral) for a given $\boldsymbol{r}, \boldsymbol{S}$ and $\boldsymbol{T}$, coupon payments do not change the implied volatilities $\boldsymbol{\sigma}$ (and the variance of the collateral).

\footnotetext{
${ }^{18} \boldsymbol{r}, \boldsymbol{S}$ and $\boldsymbol{T}$ are observable in our model
} 
Figure 5 summarizes and visualizes the logic of the proof:

Present value of all coupon payments can be compounded forward to time $\mathbf{T}$ to get the future value of this liability

\section{$\downarrow$}

The total liability of the Farm Credit System is the sum of the face value AND the future value of all coupon payments at time $\mathbf{T}$

\section{$\downarrow$}

The coupon payments will raise the strike price of the put by the amount of the future value of all coupon payments
The relationship between the strike price and the implicit put option price is linear
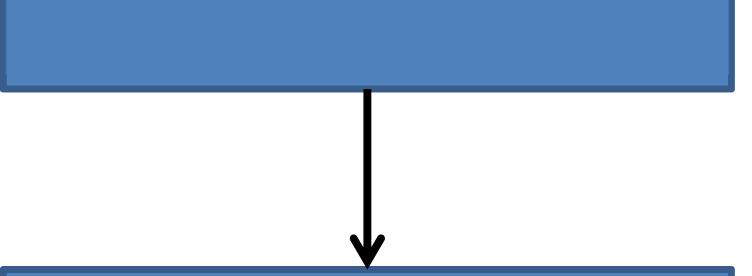

The ONLY possible way to ensure a linear relationship between the put price derived by the Black-Scholes Model and the strike price is that the implied volatility does not change with the strike price

\section{Coupon Payments do not change the implied volatilities}

Figure 5 Coupon payments and the implied volatilities 


\section{Example}

On January $27^{\text {th }}$ 2011, the Federal Farm Credit Banks Funding Corporation issued a 10Year bullet bond with the coupon rate of 3.91\%. The yield-to-maturity for this bond was $3.675 \%$. The 10 -Year Treasury yield on this day was $3.42 \%$. The spread between the bond yield and the treasury yield was $0.255 \%$.

Based on continuously compounded interests, the market value of a bond with a face value of $\$ 100$ was

$$
B P(0)=L(0)=\sum_{t=0}^{20} 100 * 3.91 \% * e^{-\frac{3.675 \%}{2} * t}+100 e^{-3.675 \% * 10}=101.915
$$

This liability in 10 years would be

$$
L(T)=101.915 * e^{3.675 \% * 10}=147.18
$$

The strike price of the put was the future value of the liability which was $\$ 147.18$. Therefore, the put price for a bond with a face value of $\$ 100$ was

$$
P(0)=\left(1-e^{-s T}\right) K e^{-r T}=\left(1-e^{-0.255 \% * 10}\right) 147.18 e^{-3.42 \% * 10}=2.63
$$

The liability of the Farm Credit System on January $27^{\text {th }} 2011$ for a bond with the face value of $\$ 100$ was equal to the bond price at time $\mathbf{0}$ which was $\$ \mathbf{1 0 1} .915$.

The collateral $\boldsymbol{A}(\mathbf{0})$ required for a bond with the face value of $\$ 100$ was

$$
A(0)=1.03 * L(0)=1.03 * 101.915=104.97
$$


Plugging the collateral value $\$ \mathbf{1 0 4}$. 97, the strike price of the put option $\mathbf{\$ 1 4 7 . 1 8}$, the maturity 10 years, the risk-free interest rate $\mathbf{3 . 4 2 \%}$ and the implicit put price $\mathbf{\$ 2 . 6 3}$ into the Black-Scholes Model to get the implied volatilities, which is $\mathbf{2 . 1 5 \%}$.

If the coupon payments were ignored, the strike price of the put option was the face value of the bond. The put price for a bond with a face value of $\$ 100$ was $\$ 1.79$.

$$
P(0)=\left(1-e^{-s T}\right) K e^{-r T}=\left(1-e^{-0.255 \% * 10}\right) 100 e^{-3.42 \% * 10}=1.79
$$

The liability of the Farm Credit System on January $27^{\text {th }} 2011$ for a bond with the face value of \$100 was equivalent to the money received for this bond.

$$
L(0)=B e^{-r T}-P(0)=100 * e^{-3.42 \% * 10}-1.79=69.25
$$

The collateral $\boldsymbol{A}(\mathbf{0})$ required for a bond with the face value of $\$ 100$ was

$$
A(0)=1.03 * L(0)=1.03 * 69.25=71.32
$$

The implied volatilities derived by the Black-Scholes Model was $\mathbf{2 . 1 5 \%}$ which was exactly the same as the bond with coupon payments. 
Appendix 1

$$
\begin{gathered}
K e^{-y T}=K e^{-r T}-P(0) \\
e^{-y T}=\frac{K e^{-r T}-P(0)}{K} \\
-y T=\ln \frac{K e^{-r T}-P(0)}{K} \\
y=-\frac{1}{T} \ln \frac{K e^{-r T}-P(0)}{K}
\end{gathered}
$$

\section{Appendix 2}

$$
\begin{aligned}
S=y & -r=-\frac{1}{T} \ln \frac{K e^{-r T}-P(0)}{K}-r \\
& =-\frac{1}{T} \ln \frac{K e^{-r T}-P(0)}{K}+\frac{1}{T} \ln e^{-r T} \\
& =-\frac{1}{T} \ln \left(e^{-r T}-\frac{P(0)}{K}\right)+\frac{1}{T} \ln e^{-r T} \\
= & -\frac{1}{T}\left(\ln \left(e^{-r T}-\frac{P(0)}{K}\right)-\ln e^{-r T}\right) \\
& =-\frac{1}{T} \ln \left(1-\frac{P(0)}{K e^{-r T}}\right)
\end{aligned}
$$




\section{Chapter 4}

\section{Data}

The yields of bonds with different maturities issued by the Farm Credit System are taken from the Federal Farm Credit Bank Curve which can be found on Bloomberg ${ }^{19}$. Specifically, the Federal Farm Credit Bank Curve is an index which is updated on a daily basis showing the yields of the bonds with different maturities issued by the Federal Farm Credit Banks Funding Corporations. The members of the index include the 3-Month bond, 6-Month bond, 1-Year bond, 2-Year bond, 3-Year bond, 4-Year bond, 5-Year bond, 7Year bond, 8-Year bond, 9-Year bond, 10-Year bond, 15-Year bond and 20-Year bond. The beginning date of the data is January $13^{\text {th }} 2009$ and the ending date of the data is February $10^{\text {th }} 2011$. The total number of the observations for a given maturity is 522 . The risk-free interest rates are the Daily Treasury Yield Curve Rates published on the official website of the U.S. Department of the Treasury ${ }^{20}$. Since the corresponding treasury yields are not available for the 4-Year bond, 8-Year bond, 9-Year bond and 15-Year bond, the final data set used for this research include both the treasury yield and the yield of the Farm Credit System bonds with the maturities of 3-Month, 6-Month, 1-Year, 2-Year, 3Year, 5-Year, 7-Year, 10-Year and 20-Year.

The summary statistics for the FCS bond yields are shown in Table 1:

\footnotetext{
${ }^{19}$ Bloomberg ticker YCCF0078 INDEX

${ }^{20} \mathrm{http}$ ///www.treasury.gov/resource-center/data-chart-center/interestrates/Pages/TextView.aspx?data=yield
} 


\begin{tabular}{lccccccccc}
\hline FCS yield & 3M & $\mathbf{6 M}$ & $\mathbf{1 Y}$ & $\mathbf{2 Y}$ & $\mathbf{3 Y}$ & $\mathbf{5 Y}$ & $\mathbf{7 Y}$ & $\mathbf{1 0 Y}$ & $\mathbf{2 0 Y}$ \\
\hline MAX & $0.77 \%$ & $0.88 \%$ & $1.26 \%$ & $1.95 \%$ & $2.35 \%$ & $3.66 \%$ & $4.53 \%$ & $5.23 \%$ & $5.87 \%$ \\
MIN & $0.03 \%$ & $0.10 \%$ & $0.25 \%$ & $0.46 \%$ & $0.64 \%$ & $1.45 \%$ & $2.05 \%$ & $2.84 \%$ & $3.86 \%$ \\
AVERAGE & $0.24 \%$ & $0.32 \%$ & $0.53 \%$ & $1.12 \%$ & $1.60 \%$ & $2.60 \%$ & $3.38 \%$ & $4.12 \%$ & $4.89 \%$ \\
Median & $0.19 \%$ & $0.28 \%$ & $0.44 \%$ & $1.12 \%$ & $1.71 \%$ & $2.77 \%$ & $3.60 \%$ & $4.33 \%$ & $4.97 \%$ \\
\hline
\end{tabular}

Table 1 Summary statistics for the Farm Credit System bond yields

Figure 6 and Figure 7 visualize the yields of the short-term bonds, medium-term and long-term bonds issued by the Farm Credit System, respectively.

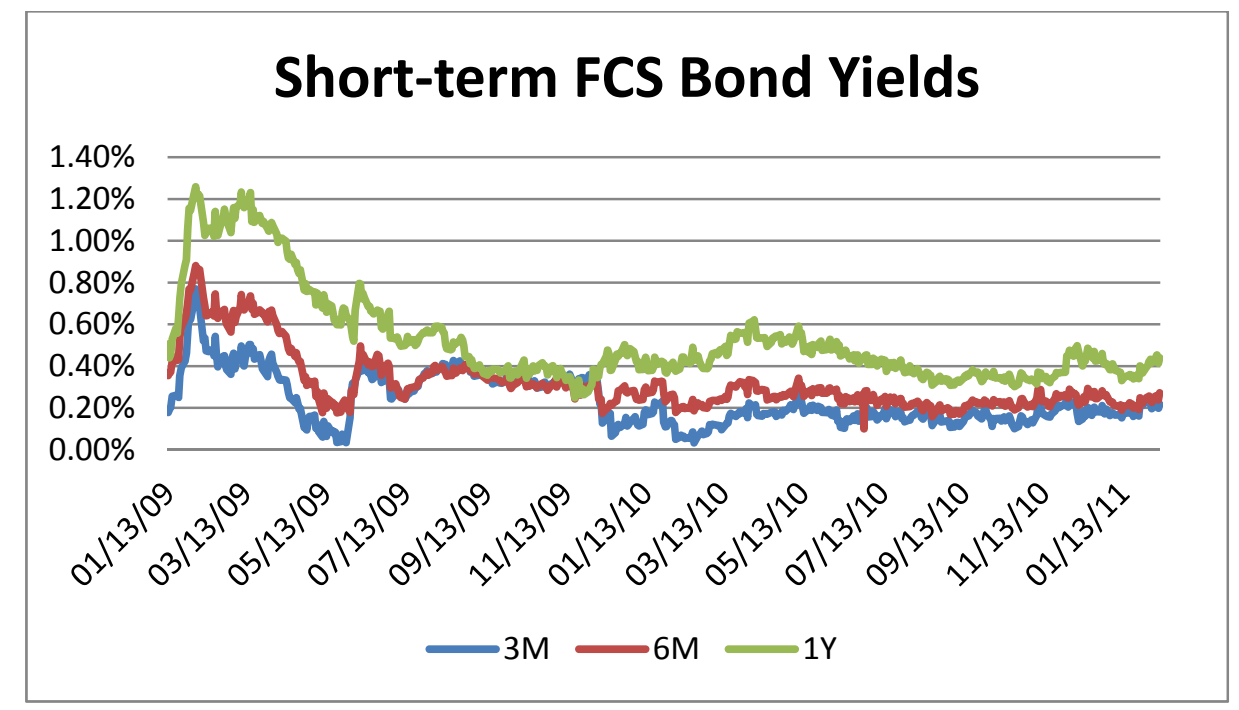

Figure 6 Short-term Farm Credit System bond yields

The Short-term bond issued by the Farm Credit System had relatively low yields in January 2009, surged to the 2-year peak in February 2009 and fell back to their beginning levels in June 2009. The yields fell continuously until the end of December 2009. From the beginning of 2010 to April 2010, the short-term bond yields experienced a moderate increase. They fell again since then. The Yields of the 3-Month, 6-Month and 1-Year bonds were almost parallel to each other from January 2009 to May 2009 and from 
December 2009 to January 2011. However, the 3-Month, 6-Month and 1-Year yields were almost the same from May 2009 to December 2009. There were days when the 3Month yield was higher than the 6-Month and 1-Year yields.

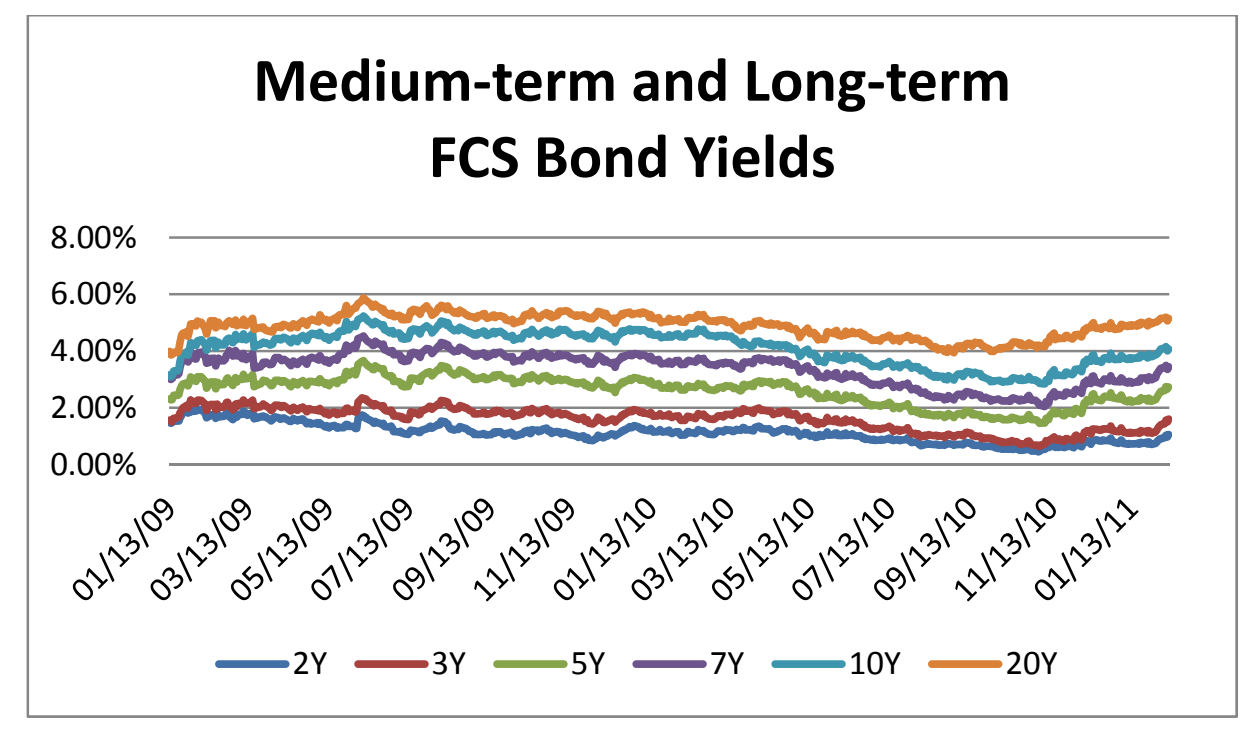

Figure 7 Medium-term and long-term Farm Credit System bond yields

The yields of the medium-term and long-term Farm Credit System bonds were more stable and almost parallel to each other. The only obvious exception is that the yields of the 3-Year bond fell more quickly than the yields of the 2-Year bond during the period July 2010 to November 2010.

The summary statistics for the spread between the treasury yield and the Farm Credit System bond yield are shown in Table 2:

\begin{tabular}{lccccccccc}
\hline Spread & 3M & $\mathbf{6 M}$ & $\mathbf{1 Y}$ & $\mathbf{2 Y}$ & $\mathbf{3 Y}$ & $\mathbf{5 Y}$ & $\mathbf{7 Y}$ & $\mathbf{1 0 Y}$ & $\mathbf{2 0 Y}$ \\
\hline MAX & $0.45 \%$ & $0.48 \%$ & $0.73 \%$ & $1.05 \%$ & $0.93 \%$ & $1.22 \%$ & $1.71 \%$ & $1.66 \%$ & $1.23 \%$ \\
MIN & $-0.15 \%$ & $-0.12 \%$ & $-0.04 \%$ & $0.09 \%$ & $0.08 \%$ & $0.16 \%$ & $0.13 \%$ & $0.22 \%$ & $0.27 \%$ \\
AVERAGE & $0.09 \%$ & $0.08 \%$ & $0.14 \%$ & $0.30 \%$ & $0.34 \%$ & $0.54 \%$ & $0.65 \%$ & $0.86 \%$ & $0.79 \%$ \\
\hline
\end{tabular}




\begin{tabular}{llllllllll}
\hline MEDIAN & $0.05 \%$ & $0.06 \%$ & $0.10 \%$ & $0.22 \%$ & $0.27 \%$ & $0.39 \%$ & $0.50 \%$ & $0.89 \%$ & $0.71 \%$ \\
\hline
\end{tabular}

Table 2 Summary statistics for spreads

It is surprising to see that the minimums for the 3-Month spread, 6-Month spread and 1Year spread are negative. Since spread is defined as the difference between the Farm Credit System bond yield and the treasury yield, a negative spread means that the Farm Credit System bond yield is smaller than the risk-free interest rate. This also means, the market is willing to accept a return which is even lower than the risk-free interest-rate to buy the short-term bonds issued by the Farm Credit system. This observation seems to be unconventional and further research is needed to explain this phenomenon.

Figure 8, Figure 9 and Figure 10 visualize the spreads between the short-term, mediumterm and long-term Treasury yields and FCS yields, respectively.

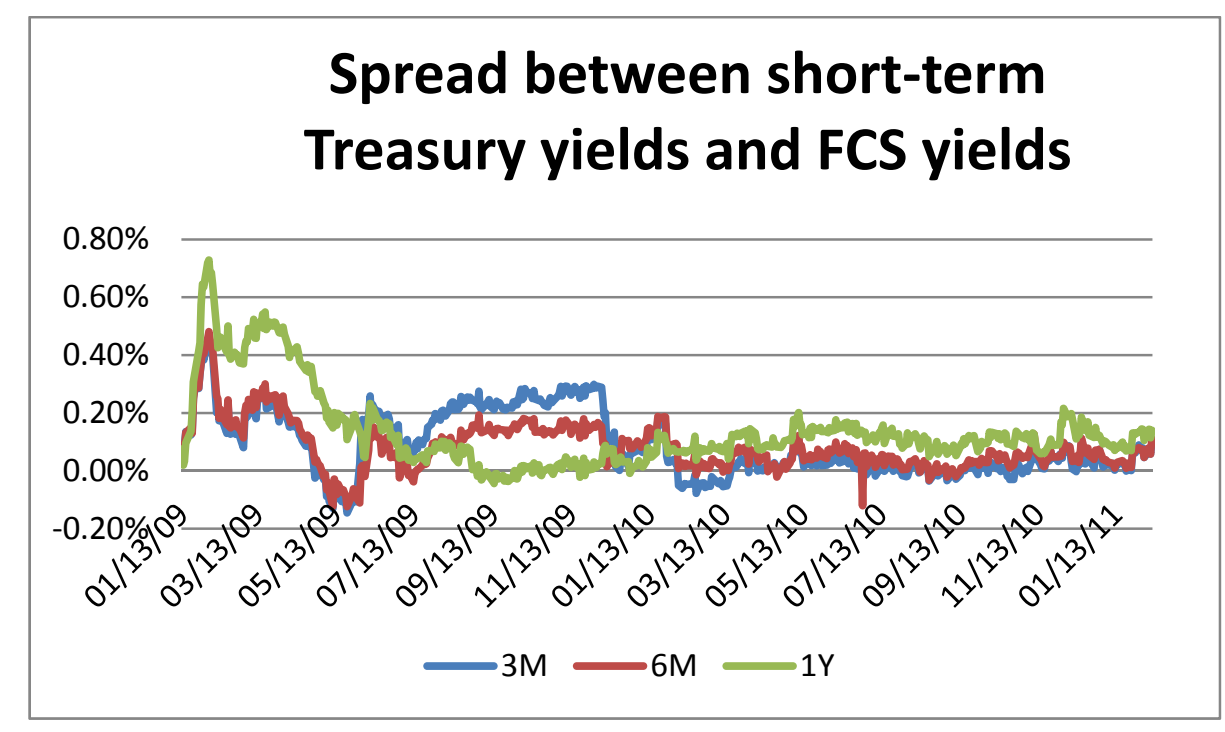

Figure 8 Spread between short-term treasury yields and FCS yields 
As shown in Figure 8, the spreads between the short-term treasury yields and FCS yields are quite different for different maturities. In order to make the comparison more systematically, the observation period will be further divided into three phases. The first phase is from January 2009 to June 2009. The second phase is from July 2009 to January 2010. The Third phase is from February 2010 to January 2011.

\section{First Phase}

The spreads for 3-Month, 6-Month and 1-Year bond had similar trends in the first phase (from January 2009 to June 2009). In this phase, the 3-Month and 6-Month spreads were very close to each other and there were days when the spreads for 3-Month and 6-Month were negative, while the 1-Year spread was much higher and positive.

One other interesting observation for this phase (January 2009 to June 2009) is that the 3Month spread became negative for the first time during the observation period on April $27^{\text {th }}$ 2009. Although the 3-Month spread became positive 1 basis point on the next day, it became negative again on April 29 2009 and remained negative for a whole month. On May $29^{\text {th }} 2009$, the 3-Month spread was still -11 basis points. However, it became 2 basis points on the next trading day and increased quickly since then.

The 6-Month spread behaved similar to the 3-Month spread in this phase (January 2009 to June 2009). It became negative on May $4^{\text {th }} 2009$, remained negative the whole month and became positive again on June $2^{\text {nd }} 2009$.

\section{Second Phase}


In this phase (July 2009 to January 2010), the 3-Month spread was the biggest from July 2009 to December $17^{\text {th }} 2009$, followed by the 6-Month spread and the 1-Year spread, which reversed the trend of the first phase. From December $18^{\text {th }} 2009$ to the end of January 2010 the 6-Month spread was the biggest.

The 3-Month and 6-Month spreads were parallel to each other and stayed positive the whole time. The 1-Year spread became negative on September $1^{\text {st }} 2009$ and remained negative until October $6^{\text {th }} 2009$ with only 3 exceptions.

On December $8^{\text {th }}$ 2009, the 3-Month spread was still 24 basis points, fell dramatically in the next 8 trading days and reached 0 basis point on December $21^{\text {st }}$ 2009. It increased again after the Christmas 2009 and reached another peak with 16 basis points on January $26^{\text {th }}$ 2010. In the meantime, the 6-Month and 1-Year spreads underwent a similar but less dramatic process. On January $26^{\text {th }}$ 2010, both the 6-Month and 1-Year spreads reached their peaks with 19 basis points and 10 basis points, respectively.

\section{Third Phase}

This phase was similar to the first phase. In this phase, the 1-Year spread became the biggest again, with the 6-Month spread and 3-Month spread close to each other. The 1Year spread was positive the whole time, while both the 3-Month spread and 6-Month spread became negative from August $20^{\text {th }} 2010$ to September $13^{\text {th }} 2010$ with a few exceptions.

One other obvious exception is that the 6-Month spread became -12 basis points on June $29^{\text {th }} 2010$ while it was 4 basis points on June $28^{\text {th }} 2010$ and 6 basis points on June $30^{\text {th }}$. 
One possible explanation for the negative spreads is that the yield curve for the FCS bonds is an interpolated curve. Therefore, if the Farm Credit System believes that the short-term interest rate is too high and expects it to decrease in the future, it will avoid choosing short-term bonds. If the FCS does not issue short-term bonds during a certain period, there will be no actual yield available for a bond with certain maturity for this period. The only way to get the yield for this specific maturity is to derive it by using onthe-run FCS bonds.

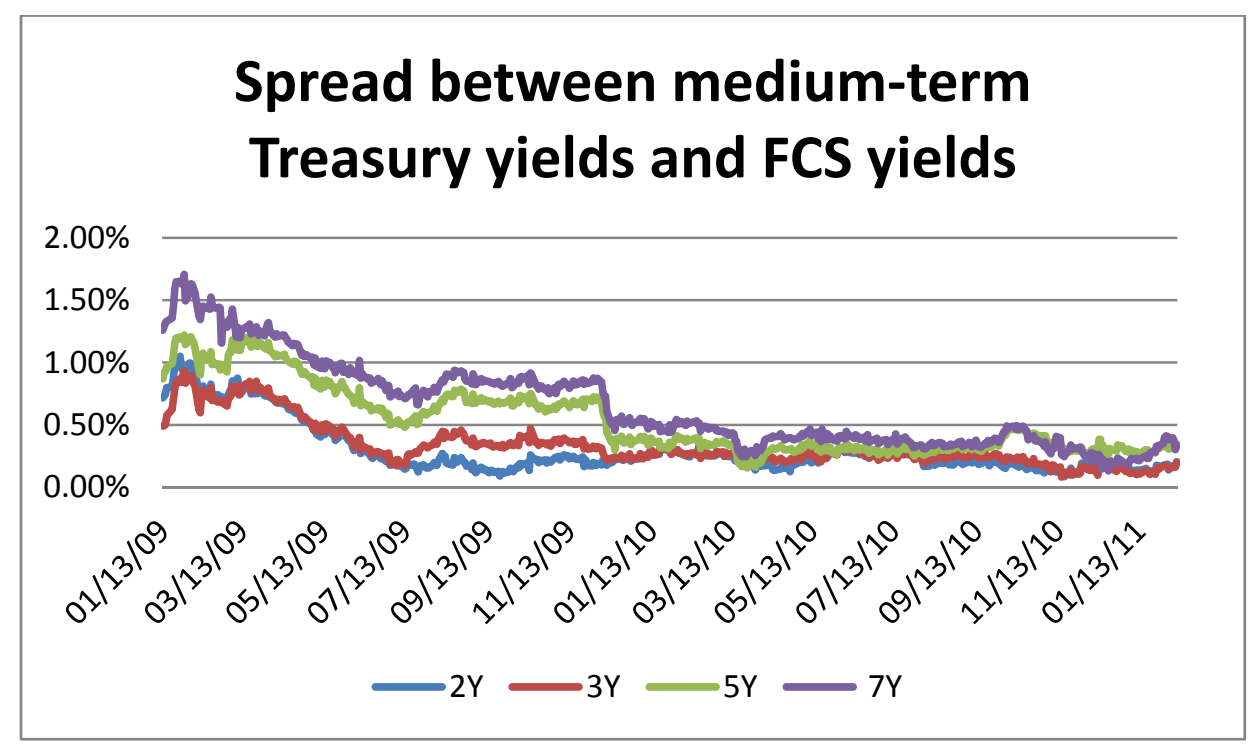

Figure 9 Spread between medium-term treasury yields and FCS yields

As shown in Figure 9, the spreads between the medium-term Treasury yields and the FCS yields had a falling trend over the whole observation period. The 2-Year spread and 3-Year spread were close to each other from January 2009 to May 2009. From June 2009 to November 2010, the 3-Year spread was much bigger than the 2-Year spread. They both converged again in December 2010 and stayed close to each other since then. The 5Year spread and 7-Year spread were much bigger than the 2-Year and 3-Year spread until 
November 2009. They fell dramatically in December 2009 and were only slightly higher than the 2-Year and 3-Year spread from that time on.

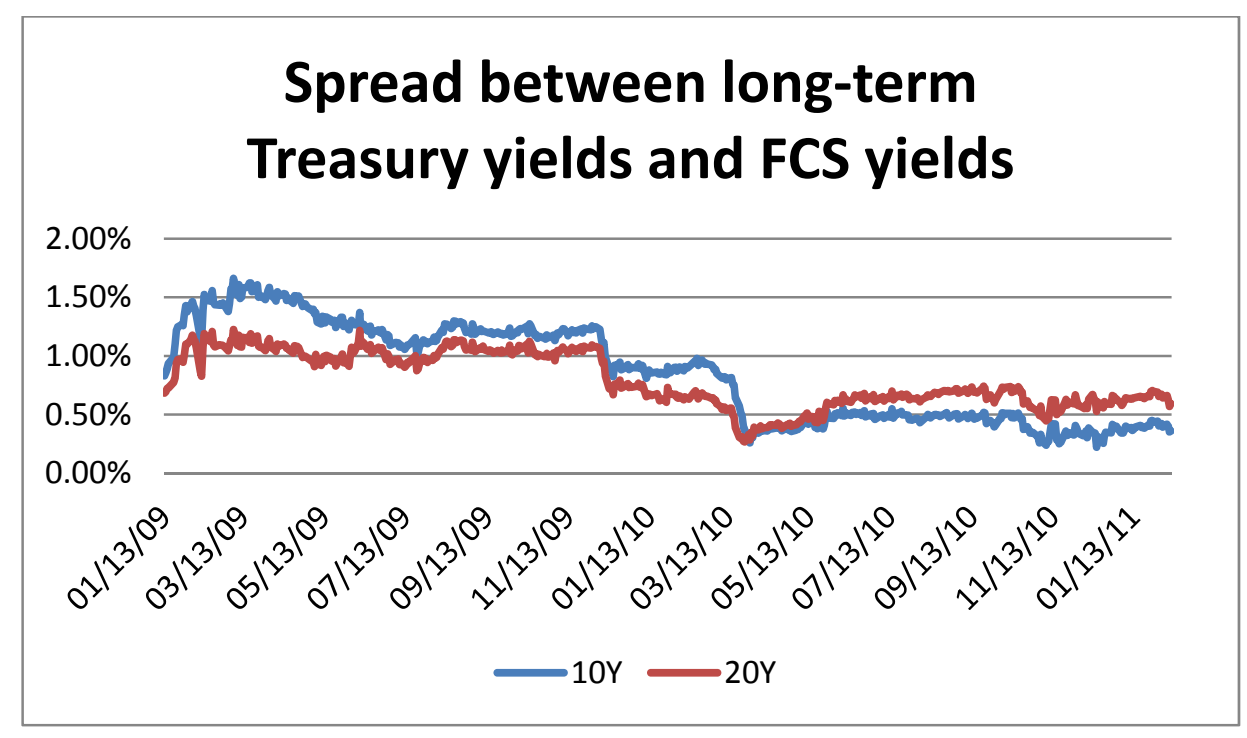

Figure 10 Spread between long-term treasury yields and FCS yields

The 10-Year spread was bigger and parallel to the 20-Year spread until the middle of March 2010. From March $16^{\text {th }} 2010$ to March $30^{\text {th }} 2010$, the 10 -Year spread underwent a sharp decline and fell from 81 basis points to 26 basis points. The 20-Year spread experienced a similar but less dramatic drop and finally exceeded the 10-Year spread on March $29^{\text {th }}$ 2010. The 20-Year spread led after that time. From April 2010 to January 2011, the 10-Year and 20-Year spread were parallel to each other again.

The historical land prices are the dollars per acre values of farm real estate in the USA published by the USDA on an annual basis ${ }^{21}$. Data are available from 1950 to 2010 .

${ }^{21}$ Bloomberg ticker: RSTEVLUS Index 


\section{Chapter 5}

\section{Results}

\subsection{Risk-free Interest rate and bond yield}

The scatter chart of risk-free interest rate and bond yield for a given maturity is presented in Figure 11 which can be found at the end of this section. The regression results with yield of a given maturity as the dependent variable and risk-free interest rate as the independent variable are also included in the graph. For Example, for the 3M bonds, the regression equation is

$$
y(3 M)=0.1166+1.0271 * r(3 M)
$$

This means, if the $3 \mathrm{M}$ risk-free interest rate increases by $1 \%$, the $3 \mathrm{M}$ bond yield will increase by 1.0271\%. However, as shown in Figure 11, the R-square is very low for 3M bond, while they are significantly higher for bonds with other maturities.

Bond yields and their corresponding risk-free interest rates are positively related. T-test results show that the risk-free interest rate of a given maturity has significant influence on the bond yield of the same maturity. This is consistent with the expectation. As shown earlier, yield is the sum of the risk-free interest rate and the spread (risk-premium). Therefore, an increase in the risk-free interest rate should push up the yield.

Moreover, even though the R-square values are higher for other maturities, they never exceed 0.82 . This should indicate that there must be some other factors which influence the bond yield and are not captured by the regression. 
According to Jacoby (2002), bond yield is also influenced by maturity, liquidity, risky coupon rate, coupon rate of a corresponding riskless bond, conditional probability of default etc. These variables might be correlated with the risk-free interest rate, but they are not perfectly correlated with the risk-free interest rate. Therefore, they need to be included in the regression. Since these variables are not included in the regression, Rsquare values for bonds with different maturities are not close to $\mathbf{1}$.

In Summary, risk-free interest rate has significant influence on the bond yield of the corresponding maturity. However, the variations of risk-free interest rates are not enough to explain the variations of bond yield. 


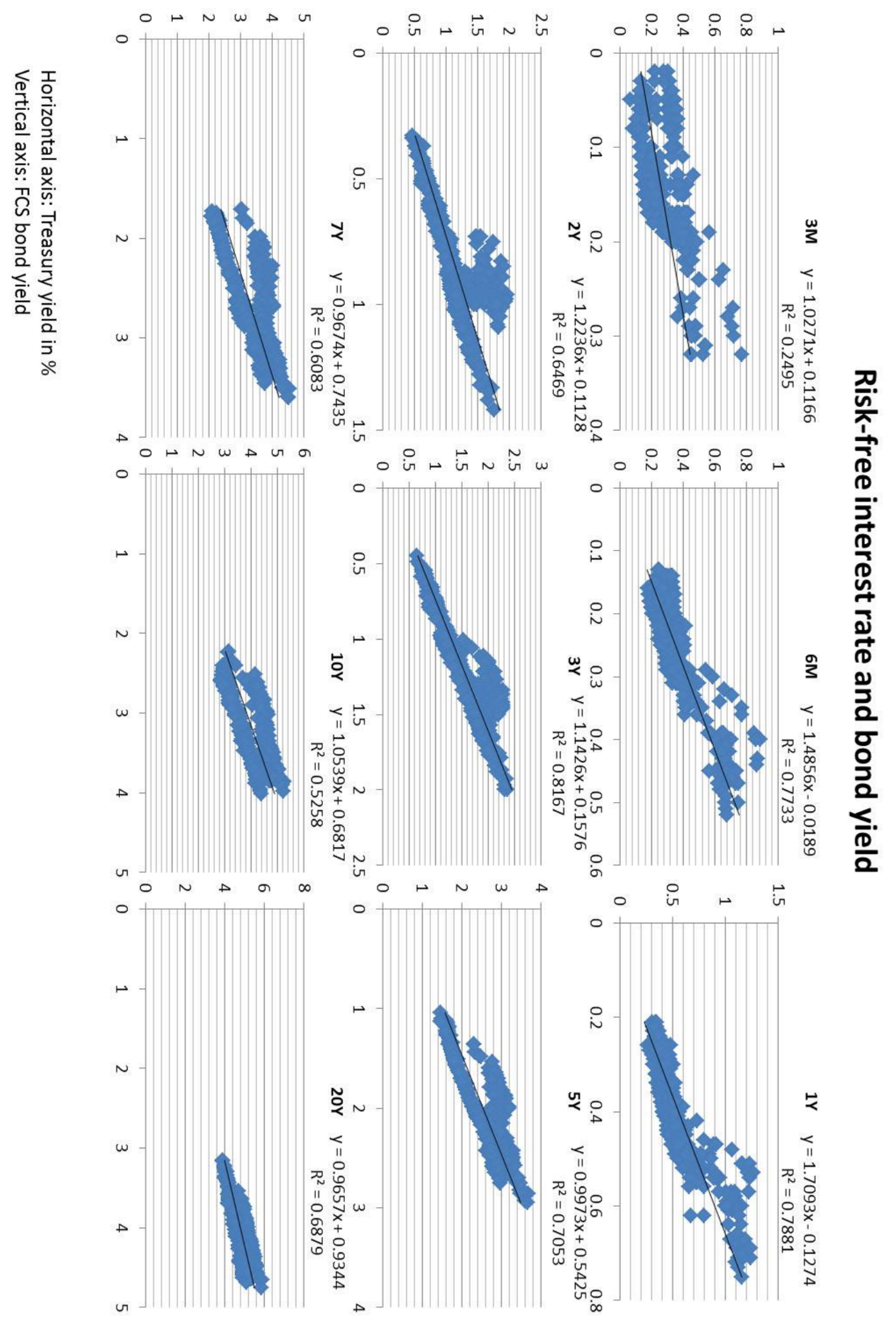

Figure 11 Relationship between risk-free interest rate and bond yield 


\subsection{Put and Spread}

The relationship between put price and spread for bonds with different maturities at the time of the bond issuance is shown in Figure 12 which can be found at the end of this section.

There are three interesting observations in Figure 12:

1. All Slopes are positive. This means, the correlation between implicit put option price and spread is positive.

2. Figure $\mathbf{1 3}$ which can be found at the end of this chapter shows that the slopes for short-term bonds are getting steeper with decreasing maturities. For Examples, if the put prices for both 3-Month bond and 6-Month bond increase by $\$ 1$, the 3Month bond is riskier relatively to the period prior to the change of the put price. Therefore, the 3-Month bond should have a higher yield (higher spread).

3. The relationship between the put price and the spread is linear for bonds with shorter maturities. The relationship between the put price and the spread becomes more complex for bonds with longer maturities. It is very obvious that the relationship between the put price and the spread for 10 -Year bond and 20-Year bond are not linear.

It is easier to use the derivatives of the spread $\boldsymbol{s}$ to the put price $\boldsymbol{P}(\mathbf{0})$ to explain these three observations.

Known from the previous chapter that 


$$
s=y-r=-\frac{1}{T} \ln \left(1-\frac{P(0)}{B e^{-r T}}\right)
$$

The derivatives of the spread $\boldsymbol{s}$ to the put price $\boldsymbol{P}(\mathbf{0})$ is

$$
\frac{\partial s}{\partial p(0)}=\frac{1}{T} \frac{1}{B e^{-r T}}\left(\frac{B e^{-r T}}{B e^{-r T}-P(0)}\right)=\frac{1}{T} \frac{1}{B e^{-r T}-P(0)},
$$

which is the product of $\frac{\mathbf{1}}{\boldsymbol{T}}$ and $\frac{\mathbf{1}}{\boldsymbol{B e}^{-\boldsymbol{r T}}-\boldsymbol{P}(\mathbf{0})}$.

Since both terms are always bigger than 0 , the product of these two terms should be bigger than 0 . This explains observation 1.

The term $\frac{\mathbf{1}}{\boldsymbol{T}}$ decreases with increasing maturity. $\boldsymbol{B} \boldsymbol{e}^{-\boldsymbol{r} \boldsymbol{T}}-\boldsymbol{P}(\mathbf{0})$ is the market value of the liabilities at time $\mathbf{0}$. The term $\frac{\mathbf{1}}{\boldsymbol{B \boldsymbol { e } ^ { - \boldsymbol { r } \boldsymbol { T } } - \boldsymbol { P } ( \mathbf { 0 } )}}$ is the inverse of the liabilities at time $\mathbf{0}$. Data used for the research show that the market value of the liabilities at time $\mathbf{0}$ is very close to the face value of the bond, if the maturity is short enough. For a short-term bond with the face value of $\$ 1$, the term $\boldsymbol{B} \boldsymbol{e}^{-\boldsymbol{r} \boldsymbol{T}}-\boldsymbol{P}(\mathbf{0})$ should be close to 1. The inverse of a number which is close to 1 should be slightly above 1 . Therefore, if the maturity is small enough, the term $\frac{1}{B \boldsymbol{e}^{-\boldsymbol{r} T}-\boldsymbol{P ( 0 )}}$ does not change much have no significant influence on the product of $\frac{\mathbf{1}}{\boldsymbol{T}}$ and $\frac{\mathbf{1}}{\boldsymbol{B} \boldsymbol{e}^{-\boldsymbol{r T}}-\boldsymbol{P}(\mathbf{0})}, \frac{\mathbf{1}}{\boldsymbol{T}}$ should be the dominating factor. This should explain observation 2 .

However, with increasing maturities, the value of the liabilities $\boldsymbol{B} \boldsymbol{e}^{-\boldsymbol{r} \boldsymbol{T}}-\boldsymbol{P}(\mathbf{0})$ will diverge more and more from its face value $\$ 1$ at the time of the bond issuance. The term $\frac{\mathbf{1}}{\mathbf{B e}^{-\mathbf{r T}}-\mathbf{P}(\mathbf{0})}$ will get bigger and bigger. At the same time, the term $\frac{\mathbf{1}}{\mathbf{T}}$ will get smaller and smaller with increasing maturities, but it is still big enough to have significant influence 
on the slope of the curve. When maturity gets big enough, both $\frac{\mathbf{1}}{\mathbf{T}}$ and $\frac{\mathbf{1}}{\mathbf{B e}^{-\mathbf{r T}}-\mathbf{P}(\mathbf{0})}$ will have significant influence on the slope of the curve. However, the influences of these two factors work against each other. For a given spread, risk-free interest rate will determine which factor dominates. Since risk-free interest rates vary over time, the relationship between spread and put gets more complex. 


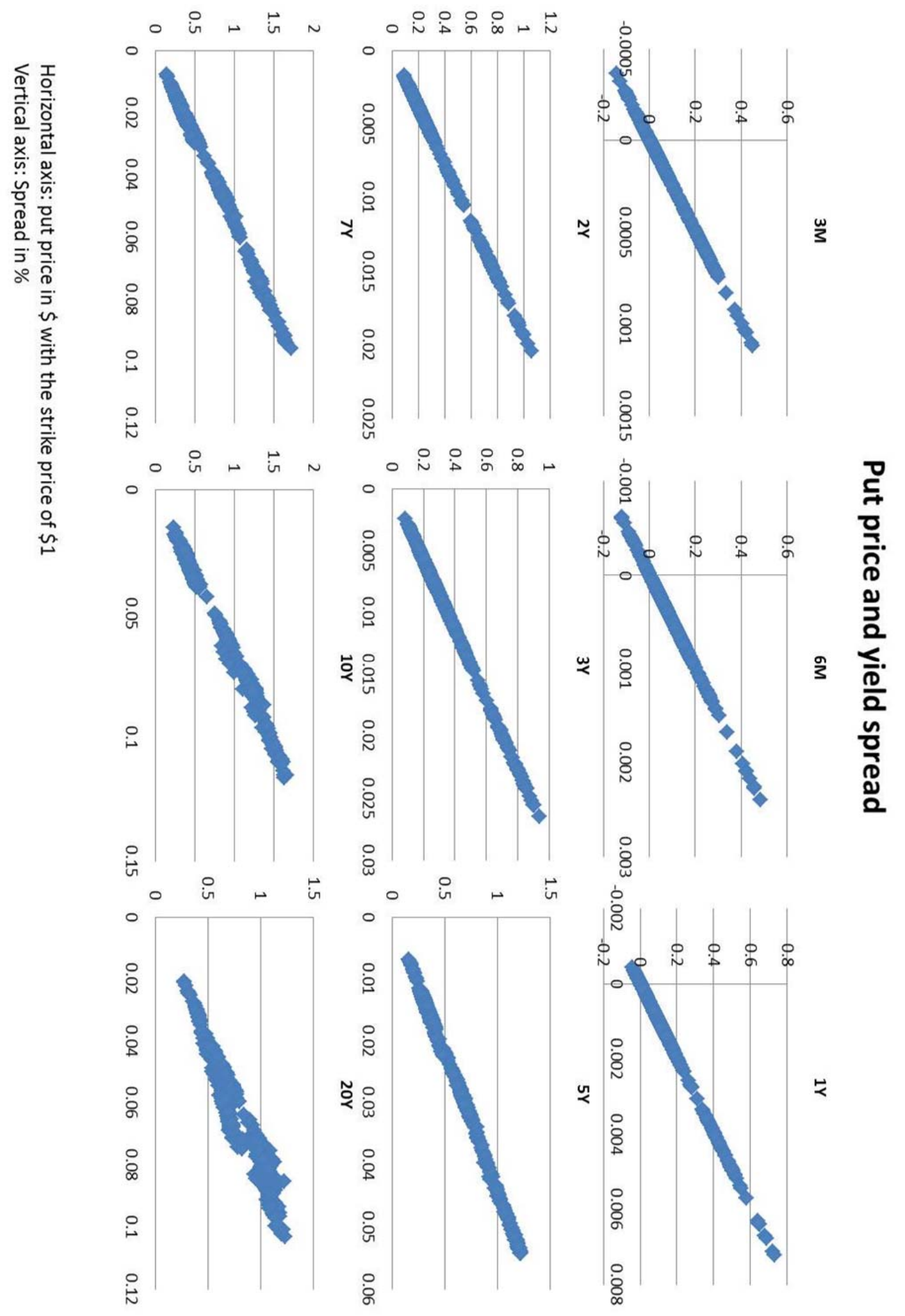

Figure 12 Relationship between put price and yield spread 


\section{Put and Spread 3M}

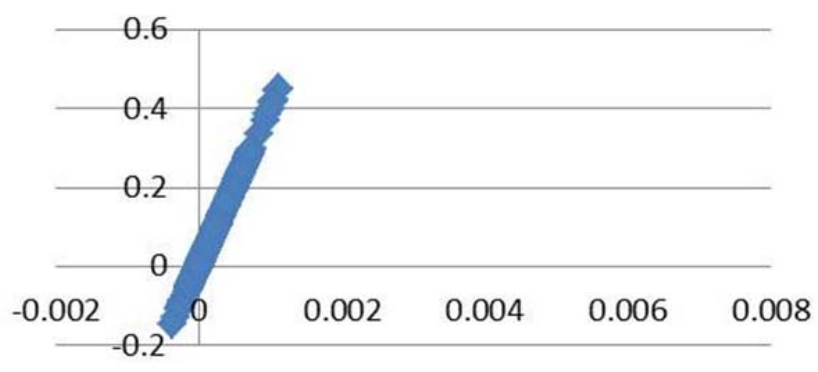

\section{Put and Spread 6M}

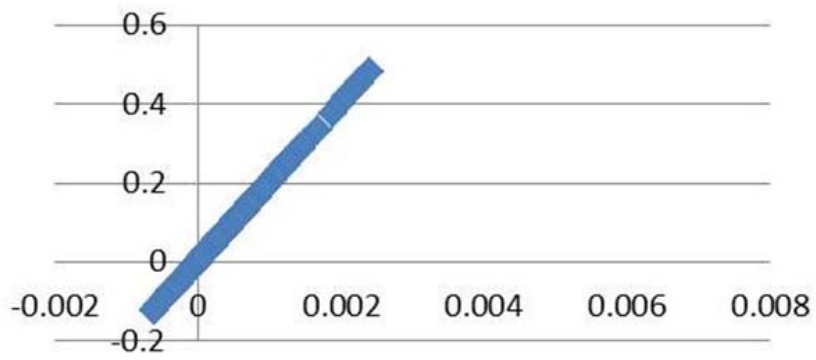

\section{Put and Spread 1Y}

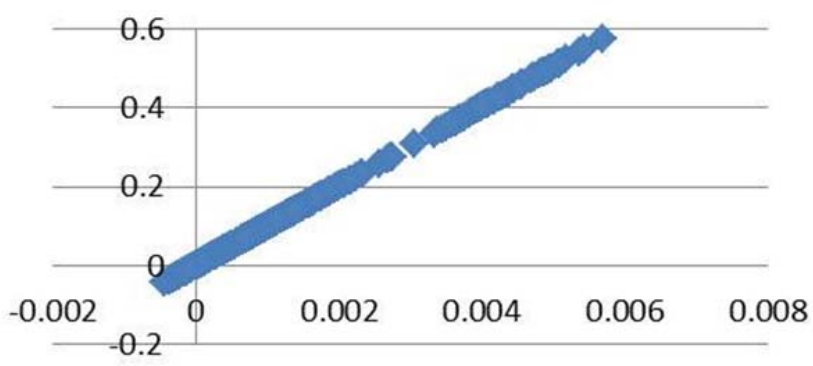

Figure 13 Put price and spread adjusted to the same scale 


\subsection{Put Price}

Since the previous chapter only investigates the relationship between put price and spread of a given maturity, the influences of spreads and risk-free interest rates of all other maturities are left out of the picture. Equation (9) shows that the relationship between spread and interest rate of the same maturity is non-linear and it predicts that spreads and risk-free interest rates of all other maturities should not influence the put price of a given maturity. However, the explanatory power of a linear model with all available independent variables is an interesting question. This chapter will identify other factors which have influences on the put price of a given maturity and explore the explanatory power of a linear model for the put price.

In order to do this, put price for a given maturity is used as the dependent variable, while the risk-free interest rates and spreads for all maturities are used as independent variables. In total, there are 9 regressions and each of them has 18 variables. The results are presented in Figure 14 which can be found at the end of this section.

$$
\text { Put }(\mathrm{t})=\text { intercept }+\sum_{t=0.25}^{20} a_{t} \mathrm{r}_{t}+\sum_{t=0.25}^{20} b_{t} s_{t}
$$

As explained in the previous section, short-term risk-free interest rate has very little influence on the put price of the corresponding maturity. This is reconfirmed by the regression results. For example, for a $3 \mathrm{M}$ put, the coefficient of the $3 \mathrm{M}$ treasury is $1.9 * 10^{-6}$, while the coefficient of the $3 \mathrm{M}$ spread is 0.0025 . The put price will decrease by $\$ 1.9 * 10^{-6}$ if the 3M risk-free interest rate increase by $1 \%$, but it will increase by 
$\$ 0.0025$ if the 3M spread increases by $1 \%$. For a $20 \mathrm{Y}$ put, the coefficient of the $20 \mathrm{Y}$ treasury is -0.014 and the coefficient for the $20 \mathrm{Y}$ spread is 0.072 . The put price will decrease by $\$ 0.014$ for a $1 \%$ increase in the $20 Y$ treasury yield and increase by $\$ 0.072$ by a $1 \%$ increase in the $20 Y$ spread. Despite the influence of spread still dominates, the difference between them gets smaller, the influence of risk-free interest rate plays a more important role.

It is also interesting to notice that the coefficients for bonds with longer maturities are bigger. For a $1 \%$ increase in spread, the put price for $1 \mathrm{Y}$ bond increases by $\$ 0.0099$ while the put price for $3 \mathrm{M}$ bond increases by $\$ 0.0025$. This is also consistent with the results of the previous chapter(Please refer to Figure 13, slopes are steeper for bonds with shorter maturities ${ }^{22}$ ).

The R-square values for all regressions are presented below:

\begin{tabular}{llllllllll}
\hline & $3 \mathbf{M}$ & $\mathbf{6 M}$ & $\mathbf{1 Y}$ & $\mathbf{2 Y}$ & $\mathbf{3 Y}$ & $\mathbf{5 Y}$ & $\mathbf{7 Y}$ & $\mathbf{1 0 Y}$ & $\mathbf{2 0 Y}$ \\
\hline $\mathbf{R}^{2}$ & 1.000000 & 1.000000 & 0.999999 & 0.999996 & 0.999988 & 0.999943 & 0.999847 & 0.999636 & 0.998733 \\
& & & & & & & & & \\
\hline
\end{tabular}

Table 3 R-square values for a linear regression model for put price

It is shown that R-square values are close to 1 for all maturities. Therefore, a linear function does a good job in explaining the put price variations of different maturities, even though the formula used to calculate the put price is not a linear function and only dependent on the spread and risk-free interest rate of a given maturity (please refer to equation (9)).

\footnotetext{
${ }^{22}$ It is important to notice that spreads are on the vertical axis.
} 
Moreover, since R-square values are bigger for bonds with shorter maturities, the prices for put options with shorter maturities could be better predicted using this model.

One last important observation is that in addition to the treasury yield and the spread of a given maturity, the treasury yield and the spread of some other maturities also have significant but small influences on the put price. This should be explained by the complex correlations between treasury yields/spreads for different maturities. Correlation matrix for treasury yields and spreads of different maturities are presented in Figure $\mathbf{1 5}$ and Figure 16 which can be found at the end of this section, respectively. 


\begin{tabular}{|c|c|c|c|c|c|c|c|c|c|c|c|}
\hline \multicolumn{4}{|c|}{$3 M$} & \multicolumn{4}{|c|}{$6 \mathrm{M}$} & \multicolumn{4}{|c|}{$1 Y$} \\
\hline Variable & Estimate & $\mathrm{t}$-value & significance & Variable & Estimate & t-value & significance & Variable & Estimate & t-value & significance \\
\hline Intercept & $1.94003 \mathrm{E}-07$ & 2.59 & YES & Intercept & $6.54787 \mathrm{E}-07$ & 1.98 & YES & Intercept & $1.22878 \mathrm{E}-05$ & 5.56 & YES \\
\hline treasury 3M & $-1.90498 \mathrm{E}-06$ & -16.01 & YES & treasury $3 \mathrm{M}$ & $-4.63445 E-06$ & -8.81 & YES & treasury $3 \mathrm{M}$ & $-1.00185 E-05$ & -2.86 & YES \\
\hline treasury $6 \mathrm{M}$ & $9.70698 \mathrm{E}-07$ & 5.86 & YES & treasury $6 \mathrm{M}$ & $1.33985 \mathrm{E}-06$ & 1.83 & NO & treasury $6 \mathrm{M}$ & $2.46426 \mathrm{E}-06$ & 0.50 & NO \\
\hline treasury $1 Y$ & 3.82728E-07 & 3.67 & YES & treasury $1 Y$ & $-3.22118 \mathrm{E}-07$ & -0.70 & NO & treasury $1 Y$ & $-3.56512 E-05$ & -11.61 & YES \\
\hline treasury $2 \mathrm{Y}$ & $-3.41231 \mathrm{E}-07$ & -3.26 & YES & treasury $2 Y$ & $-5.89236 \mathrm{E}-07$ & -1.27 & NO & treasury $2 \mathrm{Y}$ & $1.80877 \mathrm{E}-05$ & 5.86 & YES \\
\hline treasury $3 Y$ & $2.77693 \mathrm{E}-07$ & 2.39 & YES & treasury $3 Y$ & $1.04715 \mathrm{E}-06$ & 2.04 & YES & treasury $3 Y$ & $-9.98298 E-06$ & -2.91 & YES \\
\hline treasury $5 Y$ & $-1.2342 \mathrm{E}-07$ & -1.20 & NO & treasury $5 Y$ & $-4.86865 E-07$ & -1.07 & NO & treasury $5 Y$ & $2.7536 \mathrm{E}-06$ & 0.91 & NO \\
\hline treasury $7 Y$ & $8.26825 E-08$ & 0.96 & NO & treasury $7 Y$ & $1.07954 \mathrm{E}-06$ & 2.84 & YES & treasury $7 Y$ & $1.0204 \mathrm{E}-05$ & 4.02 & YES \\
\hline treasury $10 \mathrm{Y}$ & $-1.46669 \mathrm{E}-07$ & -1.46 & NO & treasury $10 \mathrm{Y}$ & $-1.76419 \mathrm{E}-06$ & -3.97 & YES & treasury $10 \mathrm{Y}$ & $-1.39191 \mathrm{E}-05$ & -4.70 & YES \\
\hline treasury20Y & $7.36196 \mathrm{E}-08$ & 1.45 & NO & treasury20Y & $8.21002 \mathrm{E}-07$ & 3.65 & YES & treasury20Y & $3.98501 \mathrm{E}-06$ & 2.66 & YES \\
\hline Spread 3M & 0.002498628 & 30514.19 & YES & Spread 3M & $-1.27939 \mathrm{E}-06$ & -3.54 & YES & Spread 3M & $-4.47222 \mathrm{E}-06$ & -1.85 & NO \\
\hline Spread 6M & $-2.60684 E-07$ & -2.74 & YES & Spread 6M & 0.004991661 & 11862.34 & YES & Spread $6 \mathrm{M}$ & $-1.78329 \mathrm{E}-05$ & -6.35 & YES \\
\hline Spread $1 Y$ & $-3.37591 E-07$ & -5.57 & YES & Spread $1 Y$ & $-1.80482 E-06$ & -6.74 & YES & Spread $1 Y$ & 0.009936432 & 5559.70 & YES \\
\hline Spread $2 Y$ & $-5.35296 E-08$ & -0.92 & NO & Spread 2Y & $-9.19261 E-07$ & -3.59 & YES & Spread $2 Y$ & $2.86098 E-08$ & 0.02 & NO \\
\hline Spread $3 Y$ & $7.57761 E-08$ & 1.07 & NO & Spread 3Y & $6.38233 \mathrm{E}-07$ & 2.04 & YES & Spread $3 Y$ & $-2.1302 \mathrm{E}-06$ & -1.02 & NO \\
\hline Spread $5 Y$ & $-2.36548 \mathrm{E}-08$ & -0.43 & NO & Spread 5Y & $-4.19204 \mathrm{E}-08$ & -0.17 & NO & Spread 5Y & $-1.88225 E-07$ & -0.12 & NO \\
\hline Spread $7 Y$ & $-1.29302 \mathrm{E}-07$ & -2.66 & YES & Spread $7 Y$ & $-4.50386 \mathrm{E}-08$ & -0.21 & NO & Spread $7 Y$ & $5.90452 \mathrm{E}-06$ & 4.11 & YES \\
\hline Spread $10 \mathrm{Y}$ & $-1.00912 \mathrm{E}-07$ & -3.01 & YES & Spread $10 \mathrm{Y}$ & $-5.80392 E-07$ & -3.92 & YES & Spread 10Y & $-5.36025 E-06$ & -5.43 & YES \\
\hline Spread $20 Y$ & 7.87973E-08 & 1.67 & NO & Spread 20Y & $4.75702 \mathrm{E}-07$ & 2.28 & YES & Spread 20Y & $-3.94317 E-07$ & -0.28 & No \\
\hline \multicolumn{4}{|c|}{$2 Y$} & \multicolumn{4}{|c|}{$3 Y$} & \multicolumn{4}{|c|}{$5 Y$} \\
\hline Variable & Estimate & $t$-value & significance & Variable & Estimate & t-value & significance & Variable & Estimate & $t$-value & significance \\
\hline Intercept & 0.00018428 & 14.69 & YES & Intercept & 0.000611051 & 20.59 & YES & Intercept & 0.002886056 & 18.96 & YES \\
\hline treasury $3 \mathrm{M}$ & $-4.6984 \mathrm{E}-05$ & -2.36 & YES & treasury $3 \mathrm{M}$ & -0.000233251 & -4.95 & YES & treasury $3 \mathrm{M}$ & -0.001608436 & -6.66 & YES \\
\hline treasury $6 \mathrm{M}$ & $3.84886 \mathrm{E}-06$ & 0.14 & NO & treasury $6 \mathrm{M}$ & $9.24052 \mathrm{E}-05$ & 1.41 & NO & treasury $6 \mathrm{M}$ & 0.000914089 & 2.72 & YES \\
\hline treasury $1 Y$ & $-4.98705 E-05$ & -2.86 & YES & treasury $1 Y$ & $-7.41216 \mathrm{E}-05$ & -1.80 & NO & treasury $1 Y$ & 0.000654317 & 3.10 & YES \\
\hline treasury $2 Y$ & -0.00014068 & -8.04 & YES & treasury $2 Y$ & -0.000133112 & -3.21 & YES & treasury $2 Y$ & -0.001408013 & -6.63 & YES \\
\hline treasury $3 Y$ & $5.76402 \mathrm{E}-05$ & 2.96 & YES & treasury $3 Y$ & -0.000125717 & -2.73 & YES & treasury $3 Y$ & 0.000768642 & 3.26 & YES \\
\hline treasury $5 Y$ & $6.90909 \mathrm{E}-06$ & 0.40 & NO & treasury $5 Y$ & $4.31883 \mathrm{E}-05$ & 1.06 & NO & treasury $5 Y$ & -0.00027206 & -1.30 & NO \\
\hline treasury $7 Y$ & $4.37194 \mathrm{E}-05$ & 3.04 & YES & treasury $7 Y$ & $2.69044 \mathrm{E}-05$ & 0.79 & No & treasury $7 Y$ & -0.000929325 & -5.32 & YES \\
\hline treasury 10Y & $-4.83554 \mathrm{E}-05$ & -2.88 & YES & treasury 10Y & $2.31574 \mathrm{E}-05$ & 0.58 & NO & treasury $10 \mathrm{Y}$ & 0.000294812 & 1.45 & NO \\
\hline treasury20Y & $-1.33995 \mathrm{E}-05$ & -1.57 & NO & treasury20Y & -0.000113824 & -5.65 & YES & treasury20Y & $-4.51951 \mathrm{E}-05$ & -0.44 & NO \\
\hline Spread 3M & $-6.50472 \mathrm{E}-06$ & -0.48 & NO & Spread 3M & $-4.60724 E-05$ & -1.42 & NO & Spread 3M & -0.000673696 & -4.06 & YES \\
\hline Spread 6M & $-8.19146 \mathrm{E}-05$ & -5.14 & YES & Spread 6M & $-9.60357 E-05$ & -2.55 & YES & Spread 6M & 0.001021396 & 5.29 & YES \\
\hline Spread $1 Y$ & $-2.28304 E-05$ & -2.25 & YES & Spread $1 Y$ & $-5.76752 E-05$ & -2.41 & YES & Spread $1 Y$ & -0.000288505 & -2.35 & YES \\
\hline Spread 2Y & 0.019498872 & 2014.40 & YES & Spread 2Y & $-4.66793 \mathrm{E}-06$ & -0.20 & NO & Spread $2 Y$ & $-6.66923 E-05$ & -0.57 & NO \\
\hline Spread $3 Y$ & $2.96982 E-05$ & 2.50 & YES & Spread $3 Y$ & 0.028559066 & 1017.06 & YES & Spread $3 Y$ & -0.000360077 & -2.50 & YES \\
\hline Spread 5Y & $-9.4228 \mathrm{E}-06$ & -1.02 & NO & Spread 5Y & $-7.77296 \mathrm{E}-05$ & -3.57 & YES & Spread 5Y & 0.044254953 & 396.69 & YES \\
\hline Spread 7Y & $-9.29052 \mathrm{E}-06$ & -1.14 & NO & Spread $7 Y$ & $8.80431 \mathrm{E}-05$ & 4.57 & YES & Spread $7 Y$ & 0.000146764 & 1.49 & NO \\
\hline Spread $10 \mathrm{Y}$ & $5.95174 E-06$ & 1.06 & NO & Spread $10 Y$ & $1.14646 \mathrm{E}-05$ & 0.87 & NO & Spread $10 \mathrm{Y}$ & 0.000175171 & 2.58 & YES \\
\hline Spread 20Y & $-1.08961 \mathrm{E}-05$ & -1.38 & NO & Spread 20Y & $-5.57715 \mathrm{E}-05$ & -2.99 & YES & Spread 20Y & -0.000822862 & -8.60 & YES \\
\hline \multicolumn{4}{|c|}{$7 Y$} & \multicolumn{4}{|c|}{$10 Y$} & \multicolumn{4}{|c|}{$20 Y$} \\
\hline Variable & Estimate & t-value & significance & Variable & Estimate & t-value & significance & Variable & Estimate & t-value & significance \\
\hline Intercept & 0.008510908 & 20.61 & YES & Intercept & 0.020845758 & 23.65 & YES & Intercept & 0.057404765 & 53.29 & YES \\
\hline treasury $3 \mathrm{M}$ & -0.003261714 & -4.98 & YES & treasury $3 \mathrm{M}$ & -0.004348495 & -3.11 & YES & treasury $3 \mathrm{M}$ & -0.005639452 & -3.30 & YES \\
\hline treasury $6 \mathrm{M}$ & 0.002059487 & 2.26 & YES & treasury $6 \mathrm{M}$ & 0.000653516 & 0.34 & NO & treasury $6 \mathrm{M}$ & 0.002652768 & 1.12 & NO \\
\hline treasury $1 Y$ & 0.001333556 & 2.33 & YES & treasury $1 Y$ & 0.007519182 & 6.14 & YES & treasury $1 Y$ & 0.007533715 & 5.04 & YES \\
\hline treasury $2 Y$ & -0.003961923 & -6.88 & YES & treasury $2 Y$ & -0.012084608 & -9.82 & YES & treasury $2 \mathrm{Y}$ & -0.009029995 & -6.01 & YES \\
\hline treasury $3 Y$ & 0.001957768 & 3.06 & YES & treasury $3 Y$ & 0.005134306 & 3.76 & YES & treasury $3 Y$ & 0.00260863 & 1.56 & NO \\
\hline treasury $5 Y$ & 0.003739113 & 6.60 & YES & treasury $5 Y$ & 0.008041246 & 6.65 & YES & treasury $5 Y$ & 0.006912075 & 4.68 & YES \\
\hline treasury $7 Y$ & -0.006488942 & -13.69 & YES & treasury $7 Y$ & -0.007959431 & -7.87 & YES & treasury $7 Y$ & -0.008299182 & -6.71 & YES \\
\hline treasury $10 \mathrm{Y}$ & 0.001644733 & 2.97 & YES & treasury $10 \mathrm{Y}$ & -0.001534818 & -1.30 & NO & treasury $10 \mathrm{Y}$ & 0.005061822 & 3.51 & YES \\
\hline treasury20Y & -0.000577045 & -2.06 & YES & treasury20Y & -0.0017718 & -2.96 & YES & treasury20Y & -0.014277511 & -19.54 & YES \\
\hline Spread 3M & -0.001165857 & -2.59 & YES & Spread 3M & -0.001007728 & -1.05 & NO & Spread 3M & -0.005530196 & -4.70 & YES \\
\hline Spread 6M & 0.001833602 & 3.50 & YES & Spread 6M & 0.001622618 & 1.45 & NO & Spread 6M & 0.007141841 & 5.22 & YES \\
\hline Spread $1 Y$ & -0.00140616 & -4.22 & YES & Spread $1 Y$ & 0.000379382 & 0.53 & NO & Spread $1 Y$ & -0.000326025 & -0.37 & NO \\
\hline Spread $2 Y$ & 0.000839359 & 2.63 & YES & Spread $2 Y$ & -0.000184483 & -0.27 & NO & Spread $2 Y$ & -0.001329311 & -1.60 & NO \\
\hline Spread $3 Y$ & -0.00043951 & -1.13 & NO & Spread $3 Y$ & 0.002472098 & 2.96 & YES & Spread $3 Y$ & 0.003021267 & 2.96 & YES \\
\hline Spread $5 Y$ & 0.00120078 & 3.97 & YES & Spread 5Y & 0.001958763 & 3.03 & YES & Spread 5Y & 0.001605676 & 2.03 & YES \\
\hline Spread $7 Y$ & 0.055099916 & 205.66 & YES & Spread $7 Y$ & -0.001075597 & -1.88 & NO & Spread 7Y & -0.002222804 & -3.18 & YES \\
\hline Spread 10Y & 0.000585541 & 3.18 & YES & Spread $10 \mathrm{Y}$ & 0.066654317 & 169.34 & YES & Spread 10Y & 0.001542284 & 3.21 & YES \\
\hline Spread 20Y & -0.002083053 & -8.03 & YES & Spread $20 \mathrm{Y}$ & -0.002712769 & -4.90 & YES & Spread 20Y & 0.072368982 & 106.93 & YES \\
\hline
\end{tabular}




\begin{tabular}{|c|c|c|c|c|c|c|}
\hline & 3M Treasury & 6M Treasury $1 Y$ Treasury & 2Y Treasury 3Y Treasury $5 Y$ Treasury & 7Y Treasury & 10Y Treasury & \\
\hline $3 M$ & 1 & 0.7985216260 .5 & 07350.0 & 1905 & & 528 \\
\hline easury & 521626 & 10 & 480.3 & +40 & & \\
\hline 1Y Treasury & 0.552601443 & 0.888033973 & 880.6 & 002 & 0.1 & 545 \\
\hline 2Y Treasury & 0.161620735 & 0.4658113480 & 10.979674780 .861007853 & 09 & 0.68 & 905 \\
\hline 3Y Treasury & 0.04355774 & 0.3236399230 .659879624 & 0.97967478 & & 0.795045173 & 7658 \\
\hline $5 Y \mathrm{~T}$ & 702516 & 0.031581 & 0.8610 & & & 274 \\
\hline $7 Y$ Treasury & -0.2 & - & 0.8 & 1 & 0.977087218 & 172 \\
\hline OY Treausry & -0.2 & -( & 470.7 & & 1 & 5056 \\
\hline oY Trea & -0.219054528 & -0.1257400070 .204008545 & 0.668769050 .7710276580 .910049274 & 0.94357172 & 0.97595056 & \\
\hline
\end{tabular}

Figure 15 Correlation matrix for treasury yields

\begin{tabular}{|c|c|c|c|c|c|c|c|c|c|}
\hline & spread 3M & Spread 6M & spread $1 Y$ & spread $2 Y$ & spread $3 Y$ & spread $5 Y$ & spread $7 Y$ & spread 10Y & spread 20Y \\
\hline spread 3M & & 0.849300822 & 20.253712579 & 90.339693767 & 70.528500517 & 70.625858222 & 20.639001995 & 50.619014159 & 90.703341718 \\
\hline Spread 6M & 0.849300822 & & 10.573391977 & $\begin{array}{ll}7 & 0.60208607\end{array}$ & 70.684225968 & 80.639904697 & 70.642017408 & .521276513 & 30.519027792 \\
\hline spread $1 Y$ & 0.253712579 & 0.573391977 & & 10.877735749 & 0.791998654 & 40.643822486 & 60.608221276 & 60.3956 & 10.315352273 \\
\hline spread $2 Y$ & 0.339693767 & 0.60208607 & 70.877735749 & & 0.928000186 & 60.806026865 & 50.812824724 & 40.609327008 & 4086 \\
\hline spread 3Y & 0.528500517 & 0.684225968 & 80.791998654 & 40.928000186 & & 10.922281002 & 0.9155178 & 0.786675 & 50.674111645 \\
\hline spread $5 Y$ & 0.625858222 & 0.639904697 & 70.643822486 & 60.806026865 & 0.922281002 & 1 & 10.97372218 & 80.888120106 & 60.845493106 \\
\hline spread 7Y & 0.639001995 & 0.642017408 & 80.608221276 & 60.812824724 & 0.9155178 & $\begin{array}{ll}8 & 0.97372218\end{array}$ & & 10.901387642 & $\begin{array}{ll}2 & 0.82978937\end{array}$ \\
\hline spread 10Y & 0.619014159 & 0.521276513 & 30.395615071 & 10.609327008 & 0.786675 & 50.888120106 & 60.901387642 & & 10.911148078 \\
\hline pread $20 \mathrm{Y}$ & 0.703341718 & 30.519027792 & 20.315352273 & 30.472944086 & 0.674111645 & 50.845493106 & $\begin{array}{ll}6 & 0.82978937\end{array}$ & 70.911148078 & \\
\hline
\end{tabular}

Figure 16 Correlation matrix for spreads 


\subsection{Implied volatility}

This chapter presents the results of the implied volatilities. As argued in chapter 3, the spread and the risk-free interest rate for a given bond on a given day will be used to calculate the implicit put price for that bond on this specific day. The implicit put price will be plugged into the Black-Scholes Model and derive the implied volatilities. Figure 17 illustrates how the implied volatility for a given maturity on a specific day is derived.

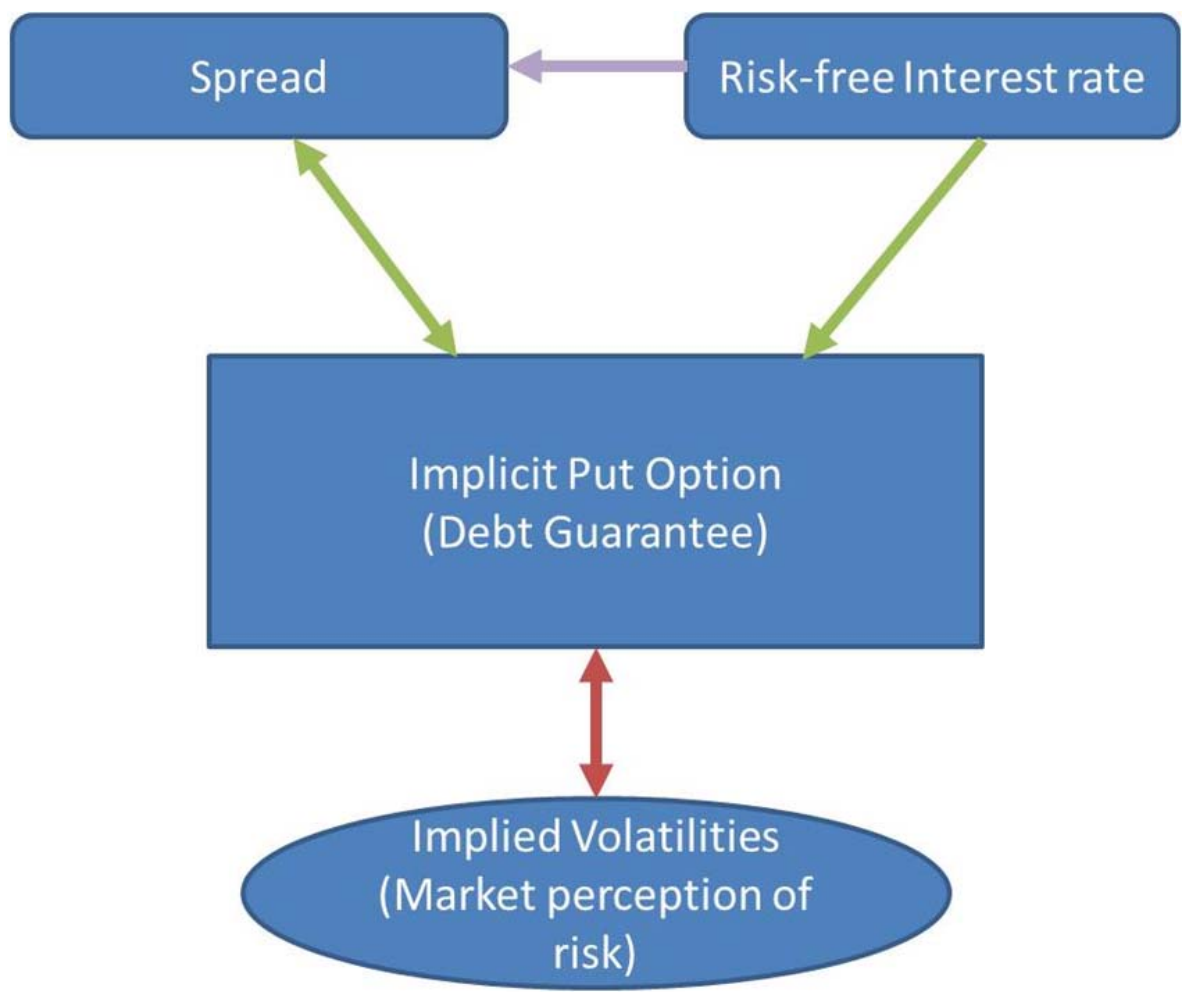

Figure 17 Calculation of the implied volatilities 
Since there are 522 observations for each maturity, 522 implied volatilities are derived for a given maturity. The summary statistics for the implied volatilities are shown in Table 4.

\begin{tabular}{lccccccccc}
\hline & $\mathbf{3 M}$ & $\mathbf{6 M}$ & $\mathbf{1 Y}$ & $\mathbf{2 Y}$ & $\mathbf{3 Y}$ & $\mathbf{5 Y}$ & $\mathbf{7 Y}$ & $\mathbf{1 0 Y}$ & $\mathbf{2 0 Y}$ \\
\hline MAX & $4.50 \%$ & $3.90 \%$ & $3.98 \%$ & $4.38 \%$ & $4.10 \%$ & $4.77 \%$ & $5.96 \%$ & $6.10 \%$ & $5.54 \%$ \\
MIN & $0.00 \%$ & $0.00 \%$ & $0.00 \%$ & $1.77 \%$ & $1.60 \%$ & $1.83 \%$ & $1.65 \%$ & $2.01 \%$ & $2.22 \%$ \\
AVERAGE & $2.65 \%$ & $2.32 \%$ & $2.16 \%$ & $2.54 \%$ & $2.56 \%$ & $3.05 \%$ & $3.37 \%$ & $4.01 \%$ & $4.17 \%$ \\
MEDIAN & $2.96 \%$ & $2.44 \%$ & $2.20 \%$ & $2.36 \%$ & $2.41 \%$ & $2.70 \%$ & $3.01 \%$ & $4.17 \%$ & $3.92 \%$ \\
\hline
\end{tabular}

Table 4 Summary statistics for the implied volatilities of different maturities

It is important to notice that since there are negative yield spreads for short-term bonds, the implicit put price for a bond with a negative yield spread cannot be calculated (negative put prices do not make sense). A negative yield spread would mean that the market expects this bond to be even safer than the risk-free treasury bonds. Therefore, the implied volatilities for bonds with negative yield spreads are assumed to be zero.

The average and median implied volatilities for different maturities are presented in Figure 18. 


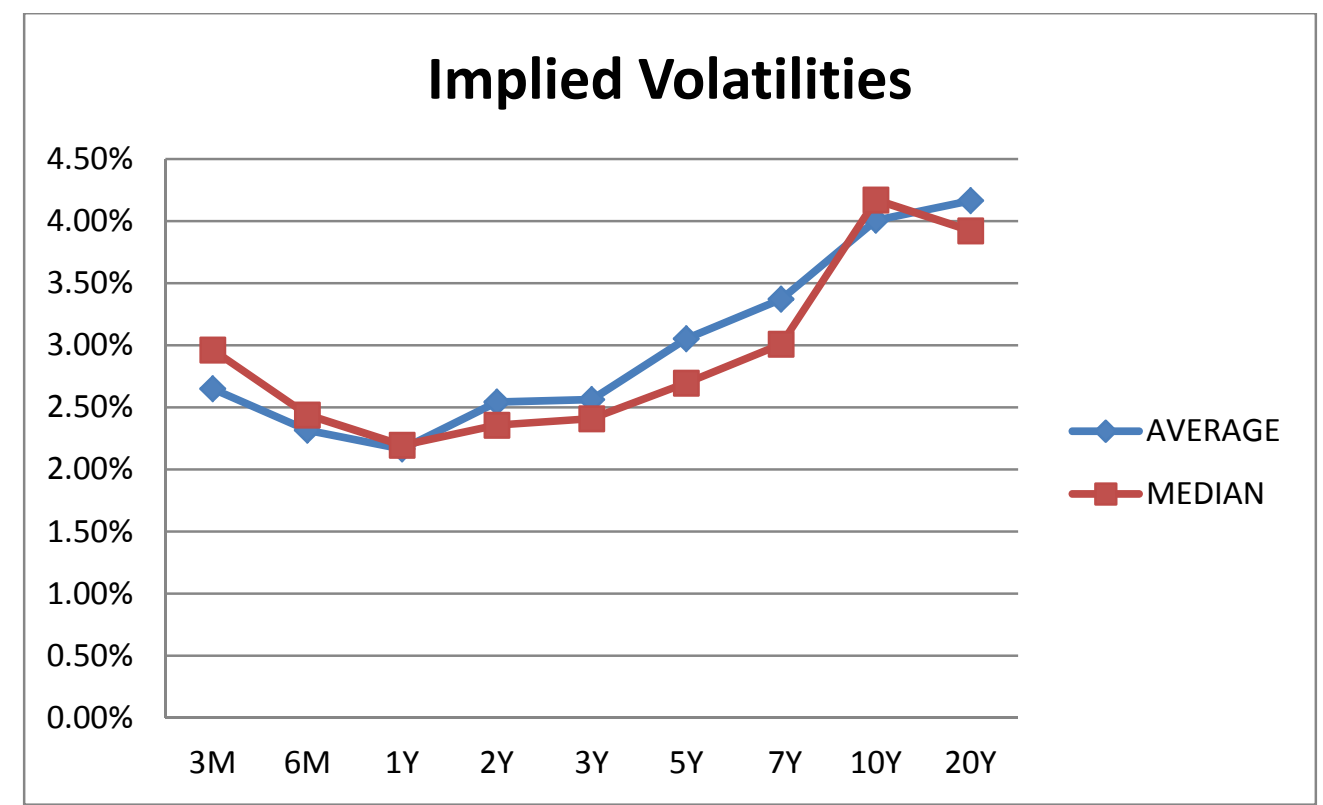

Figure 18 Average and median implied volatilities for different maturities

The average and median implied volatilities are quite close to each other for $6 \mathrm{M}, 1 \mathrm{Y}, 2 \mathrm{Y}$, $3 \mathrm{Y}$ and $10 \mathrm{Y}$ bonds, which indicate that the implied volatilities for those maturities are more evenly distributed. In contrast, the implied volatilities for 3M, 5Y, 7Y and 20Y are less evenly distributed.

Moreover, the average implied volatilities are smaller for short-term bonds, increase consistently with increasing maturities for medium-term and long-term bonds. This indicates that the market expects the volatility of the collateral value to be bigger for bonds with very short maturity, the volatility of the collateral value is the smallest for $1 \mathrm{Y}$ bond and the volatility of the collateral value increases with increasing maturity for bonds with a maturity of longer than 1 year. 


\subsection{Spread and Volatility}

The relationship between implied volatilities and spread for bonds with different maturities at the time of the bond issuance is shown in Figure $\mathbf{1 9}$ which can be found at the end of this section. This is the key part of this research, because the historical volatility of the land price will be plugged into the Black-Scholes Model in the next chapter to derive the hypothetical spread for the Farm Credit System bonds without GSE status. Therefore, it is of vital importance to understand the relationship between spread and implied volatility, which is helpful to understand the rest of this research.

According to Merton (1974), there are two forces influencing the spread of a bond for a given maturity: the variances (volatility square) of the firm's operation and the ratio of the present value (at the riskless rate) of the promised payment to the current value of the collateral, which is called as “quasi” debt to collateral value ratio in Merton’s paper.

Mathematically, Merton defines the quasi debt to collateral value ratio (d-ratio) as

$$
d=\frac{B^{-r T}}{A(0)}
$$

It is called quasi debt to collateral value ratio because $\boldsymbol{B}^{-\boldsymbol{r t}}$ does not represent the market value of the bond at time $\mathbf{0}$, which should be $\boldsymbol{B}^{-\boldsymbol{y t}}$. Therefore, the quasi debt to collateral value ratio which is defined in Merton's paper overstates the real debt to collateral value ratio. 
Figure 20 presents the results of the comparative statics analysis showing the influences of variance of the firm (volatility square) and quasi debt to collateral value ratio on the yield spread for a given maturity shown in Merton’s original paper (1974).
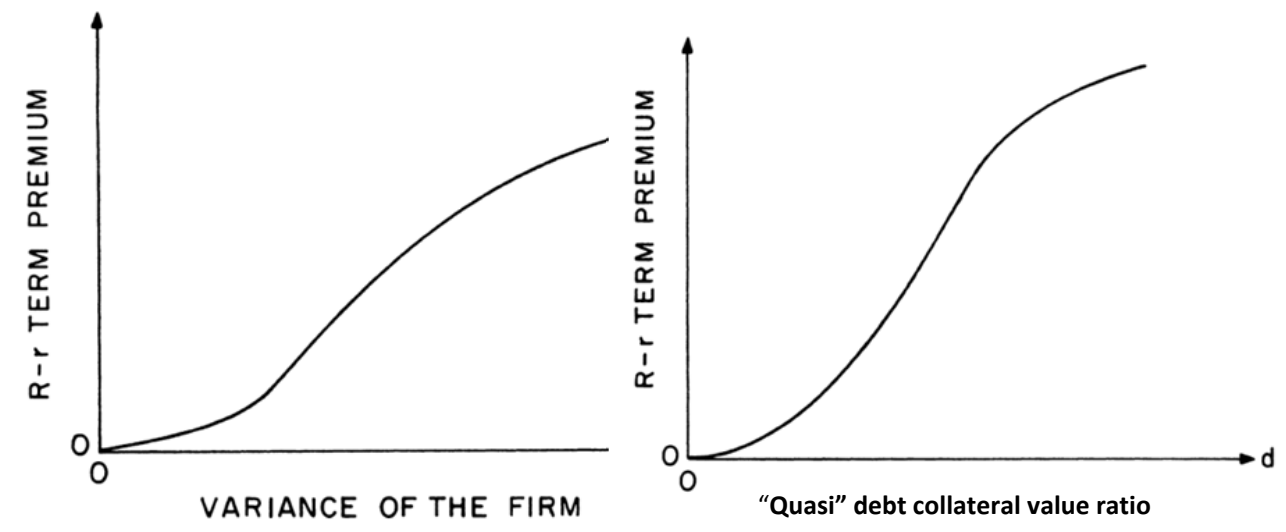

Figure 20 Impact of variance of the firm and quasi debt to collateral value ratio on the yield spread (Source: Merton(1974))

This chapter is an empirical test of Merton's theory. Based on Figure 20, for a given maturity and a given $\boldsymbol{d}$, the relationship between spread and variance (implied volatility square) should be convex first, but will become concave if variance (implied volatility square) is big enough.

Unfortunately, since both the implied volatility and $\boldsymbol{d}$ are not constant for a given maturity, Figure 19 showing the relationship between spread and implied volatility captures the influences of volatility and $\boldsymbol{d}$ simultaneously.

It can be shown that the quasi debt to collateral value ratio increases with increasing maturities. This is because the net collateral ratio is held constant at 1.03 . Therefore, the collateral value required as shown earlier is 


$$
A(0)=1.03 B e^{-y T}
$$

By a given net collateral ratio, $\boldsymbol{d}$ could be rearranged to formula

$$
d=\frac{B e^{-r T}}{1.03 B e^{-y T}}=\frac{1}{1.03} e^{s T}
$$

It shows that $\boldsymbol{d}$ of a specific bond is dependent on the net collateral ratio which is 1.03, the spread and the maturity. When the maturity is small, the spread is very small, too. The product of these two terms is close to 0 , which does not exert significant influence on $\boldsymbol{d}$. Therefore, $\boldsymbol{d}$ is close to the inverse of the net collateral ratio. The variations of quasi debt to collateral value ratios for different maturities over the observation period are presented in Figure 21 which can be found at the end this section. As shown in Figure 21, quasi debts to collateral value ratios are almost constant for short-term bonds.

In addition to Figure 21, which visualizes the variations of quasi debt to collateral value ratio for different maturities, Table 5 shows the minima and maxima of quasi debt to collateral value ratios for all maturities. The difference between the maximum and minimum for a given maturity presents the exact variations of the quasi debt to collateral value ratio:

\begin{tabular}{lccccccccc}
\hline d-ratio & $\mathbf{3 M}$ & $\mathbf{6 M}$ & $\mathbf{1 Y}$ & $\mathbf{2 Y}$ & $\mathbf{3 Y}$ & $\mathbf{5 Y}$ & $\mathbf{7 Y}$ & $\mathbf{1 0 Y}$ & $\mathbf{2 0 Y}$ \\
\hline MAX & 0.971963 & 0.973211 & 0.977974 & 0.991476 & 0.998399 & 1.03192 & 1.093999 & 1.14613 & 1.240583 \\
\hline MIN & 0.970875 & 0.970876 & 0.970875 & 0.972539 & 0.973259 & 0.978462 & 0.979948 & 0.992549 & 1.024107 \\
\hline Difference & 0.001088 & 0.002335 & 0.0071 & 0.018936 & 0.02514 & 0.053459 & 0.114051 & 0.153581 & 0.216476 \\
\hline
\end{tabular}

Table 5 Maxima and Minima of the d-ratios for all maturities 
The differences between the maxima and minima of the quasi debt to collateral value ratios are $0.001,0.002$ and 0.007 for $3 \mathrm{M}$ bond, $6 \mathrm{M}$ bond and $1 \mathrm{Y}$ bond, respectively. The variations are very small. In contrast to that, the differences between the maxima and minima are getting bigger and bigger with increasing maturities for medium-term and long-term bonds. The differences are so significant that they cannot be ignored.

Since d-ratios are almost constant for short-term bond as shown in Figure 21 and Table $\mathbf{5}$, the dominating factor influencing spreads for short-term bonds is volatility. Therefore, the graphs showing the relationship between volatility and spread of 3M, 6M and $1 \mathrm{Y}$ bonds should be consistent with the graph on the LHS of Figure 20. By comparing the corresponding graphs, it is shown that this is true ${ }^{23}$.

This does not hold for medium-term and long-term bonds: if $\boldsymbol{T}$ is getting bigger, spread $\boldsymbol{s}$ is getting bigger, too. The product of these two terms increases, $\boldsymbol{d}$ increases accordingly. Therefore, the graphs showing the relationship between spread and implied volatility for $2 \mathrm{Y}, 3 \mathrm{Y}, 5 \mathrm{Y}, 7 \mathrm{Y}, 10 \mathrm{Y}$ and $20 \mathrm{Y}$ capture the influence of volatility and the influence of $\boldsymbol{d}$ simultaneously.

Moreover, Merton shows in his paper that the relationship between spread and maturity is dependent on the value of the quasi debt to collateral value ratio.

\footnotetext{
${ }^{23}$ Please refer to Figure 22 which can be found at the end of this section.
} 


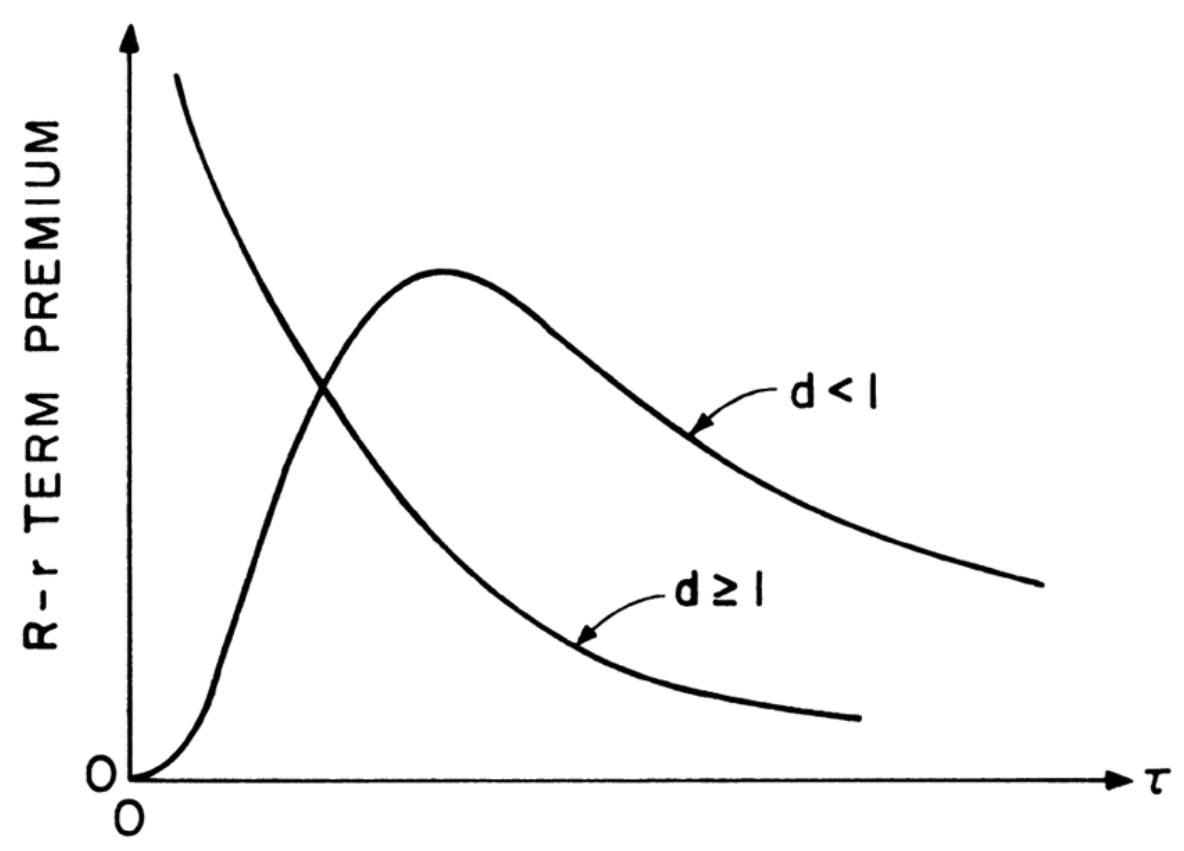

Figure 23 Impact of maturity on the yield spread (Source: Merton(1974))

As shown in Figure 23, spread decreases with increasing maturity, given the quasi debt to collateral value ratio is bigger or equal to 1 . However, it increases and then decreases with increasing maturity once the quasi debt to collateral value ratio is smaller than 1 .

Based on the quasi debt to collateral value ratio as shown in Figure 21 which can be found at the end of this section, the FCS bonds could be subdivided into three groups: bonds with maturities which are no bigger than 3 years belong to the first group. They all have quasi debt to collateral value ratios smaller than 1 over the whole observation period; $5 \mathrm{Y}$ bond and $7 \mathrm{Y}$ bond with quasi debt to collateral value ratios which are sometimes bigger than 1 and sometimes smaller than 1 belong to the second group; the third group has $10 \mathrm{Y}$ and $20 \mathrm{Y}$ bond as members which have higher-than-1 quasi debt to collateral value ratios the whole time. 
According to Merton's theory, for a given volatility and a given quasi debt to collateral value ratio, the curve describing the relationship between spreads and maturities which are no bigger than 3 years $(\mathbf{d}<\mathbf{1})$ should be bell-shaped. To test this theory, volatilities are held constant at 3\% for different maturities. Unfortunately, since both volatility and quasi debt to collateral value ratio are changing over time, it is impossible to hold these two variables constant for all maturities. However, as shown in the fourth column of Table 6, the quasi debt to collateral value ratios are almost constant for bonds with maturities which are no bigger than 3 years. Therefore, it will be treated as if it were constant. As shown in Figure 24, it displays a bell-shaped curve.

\begin{tabular}{ccccr}
\hline Maturity & Date & IV & d & Spread \\
\hline $\mathbf{3 M}$ & $7 / 13 / 2009$ & $3.0 \%$ & 0.971025 & 0.0621 \\
$\mathbf{6 M}$ & $10 / 6 / 2009$ & $3.0 \%$ & 0.971677 & 0.1653 \\
$\mathbf{1 Y}$ & $1 / 22 / 2009$ & $3.0 \%$ & 0.973868 & 0.3079 \\
$\mathbf{2 Y}$ & $5 / 26 / 2009$ & $3.0 \%$ & 0.978964 & 0.4149 \\
$\mathbf{3 Y}$ & $5 / 5 / 2009$ & $3.0 \%$ & 0.984861 & 0.4768 \\
\hline
\end{tabular}

Table 6 Relationship between spread and maturity for a given volatility and a close-toconstant d-ratio 


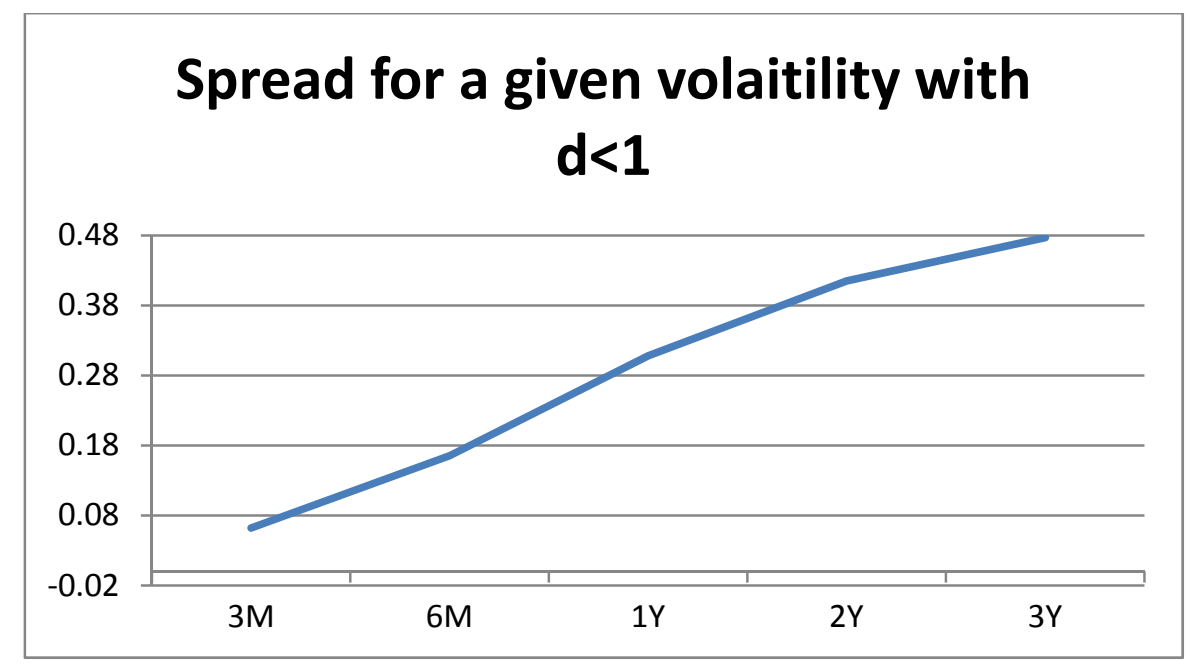

Figure 24 Relationship between maturity and spread for a given volatility and a close-toconstant d-ratio

It is hard to interpret the relationship between spread and maturity for $5 \mathrm{Y}$ and $7 \mathrm{Y}$ bonds because the quasi debt to collateral value ratio for these bonds can be either smaller or bigger than 1.

For $10 Y$ and $20 Y$ bonds, spread should decrease with increasing maturity, because they have quasi debt to collateral value ratios over 1 . However, since the quasi debt to collateral value ratio is higher for $20 \mathrm{Y}$ bond and spread increases with increasing d-ratio as shown in Figure 20, these two forces work against each other.

\begin{tabular}{ccccc}
\hline Maturity & Date & IV & d & Spread \\
\hline $\mathbf{1 0 Y}$ & $\mathbf{0 5 / 2 1 / 1 0}$ & $3.0 \%$ & 1.018633 & 0.4802 \\
$\mathbf{2 0 Y}$ & $\mathbf{1 1 / 0 8 / 1 0}$ & $3.0 \%$ & 1.06171 & 0.4472 \\
\hline
\end{tabular}

Table 7 Relationship between spread and maturity for a given volatility but various $d$ ratios 
This specific example shows that the effect of maturity dominates.

In Summary, there are three forces influencing spread: maturity, quasi debt to collateral value ratio and volatility. Spread increases with increasing quasi debt to collateral value and volatility. The influence of maturity depends on the quasi debt to collateral value and is not unambiguous.

\begin{tabular}{cccccc|cc|cc}
\hline & $\mathbf{3 M}$ & $\mathbf{6 M}$ & $\mathbf{1 Y}$ & $\mathbf{2 Y}$ & $\mathbf{3 Y}$ & $\mathbf{5 Y}$ & $\mathbf{7 Y}$ & $\mathbf{1 0 Y}$ & $\mathbf{2 0 Y}$ \\
\hline $\mathbf{d}$ & 0.9711 & 0.9713 & 0.9723 & 0.9767 & 0.9808 & 0.9974 & 1.0167 & 1.0587 & 1.1392 \\
$\mathbf{I V}$ & $2.65 \%$ & $2.32 \%$ & $2.16 \%$ & $2.54 \%$ & $2.56 \%$ & $3.05 \%$ & $3.37 \%$ & $4.01 \%$ & $4.17 \%$ \\
$\mathbf{S}$ & 0.1205 & 0.0943 & 0.1483 & 0.2965 & 0.3374 & 0.5369 & 0.6544 & 0.8577 & 0.7937 \\
\hline
\end{tabular}

Table 8 Average debt to collateral value ratios, average implied volatilities and average spreads for all maturities. It is important to notice that bonds with maturities which are no longer than $3 Y$ have a lower -than-1 d-ratio. The d-ratio for $5 Y$ and $7 Y$ bonds can be either smaller or bigger than 1.10Y and 20 Y bonds have d-ratios above 1.

$3 \mathrm{M}, 6 \mathrm{M}$ and $1 \mathrm{Y}$ bonds have almost the same average quasi debt to collateral value ratios, which are smaller than 1 . In this case, two forces influence spread: maturity and volatility.

The $3 \mathrm{M}$ bond has a higher average volatility but a lower maturity in comparison to the $6 \mathrm{M}$ bond. These two forces have opposite influences on the spread: The shorter maturity leads to a lower spread while a higher average volatility leads to a higher average spread. The data show that the average 3M spread is higher than the average 6M spread. This indicates that the impact of volatility dominates. 
The $6 \mathrm{M}$ bond has a higher average volatility but a shorter maturity in comparison to the $1 \mathrm{Y}$ bond. This is exactly the same case as the $3 \mathrm{M}$ bond and $6 \mathrm{M}$ bond pair. However, the impact of maturity on spread dominates this time.

For bonds with 2Y and 3Y maturities, all three factors influence the spread. Since both the average volatility and the average quasi debt to collateral value ratio for the $3 \mathrm{Y}$ bond are bigger than that for the $2 \mathrm{Y}$ bond, the $3 \mathrm{Y}$ bond has a higher average spread.

As shown earlier, the spreads for $5 \mathrm{Y}$ and $7 \mathrm{Y}$ are hard to interpret because the influence of maturity is not unambiguous. Even though the average quasi debt to collateral value is less than 1 for $5 \mathrm{Y}$ bond and bigger than 1 for $7 \mathrm{Y}$ bond, it is shown in Figure 21 that they could be either smaller or bigger than 1 over the observation period.

For $10 \mathrm{Y}$ and $20 \mathrm{Y}$ bonds, the quasi debt to collateral value ratios are bigger than 1 the whole time. This means, spread should decrease with increasing maturity. On the other hand, both the average debt to collateral value ratio and the average volatility are higher for $20 \mathrm{Y}$ bond, which lead to a higher spread. Therefore, the result depends on the relative magnitude of these two offsetting effects. Based on the data, the influence of maturity dominates; the average spread for the $10 \mathrm{Y}$ bond is higher than the average spread for the $20 \mathrm{Y}$ bond. 


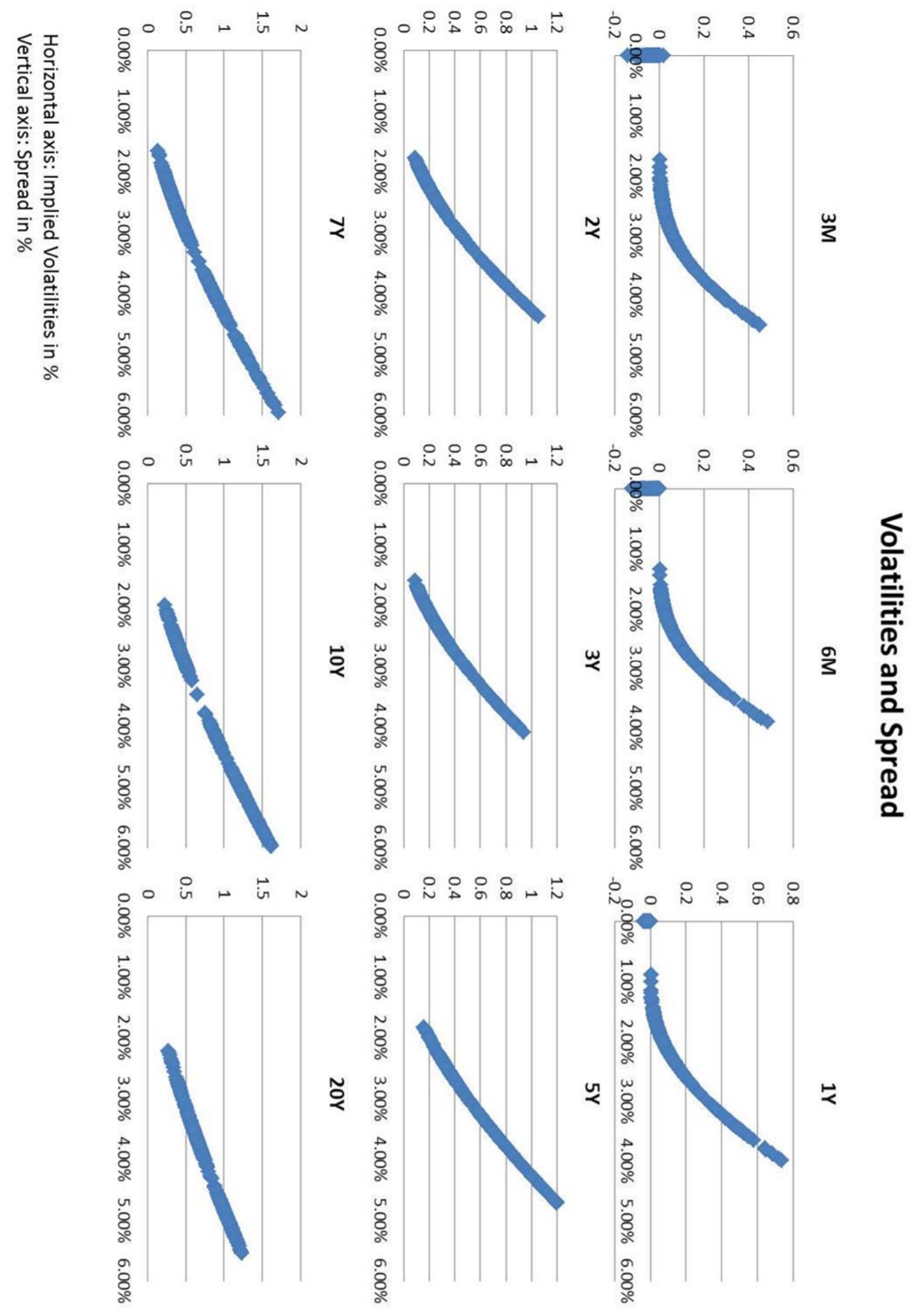

Figure 19 Relationship between volatilities and spread 


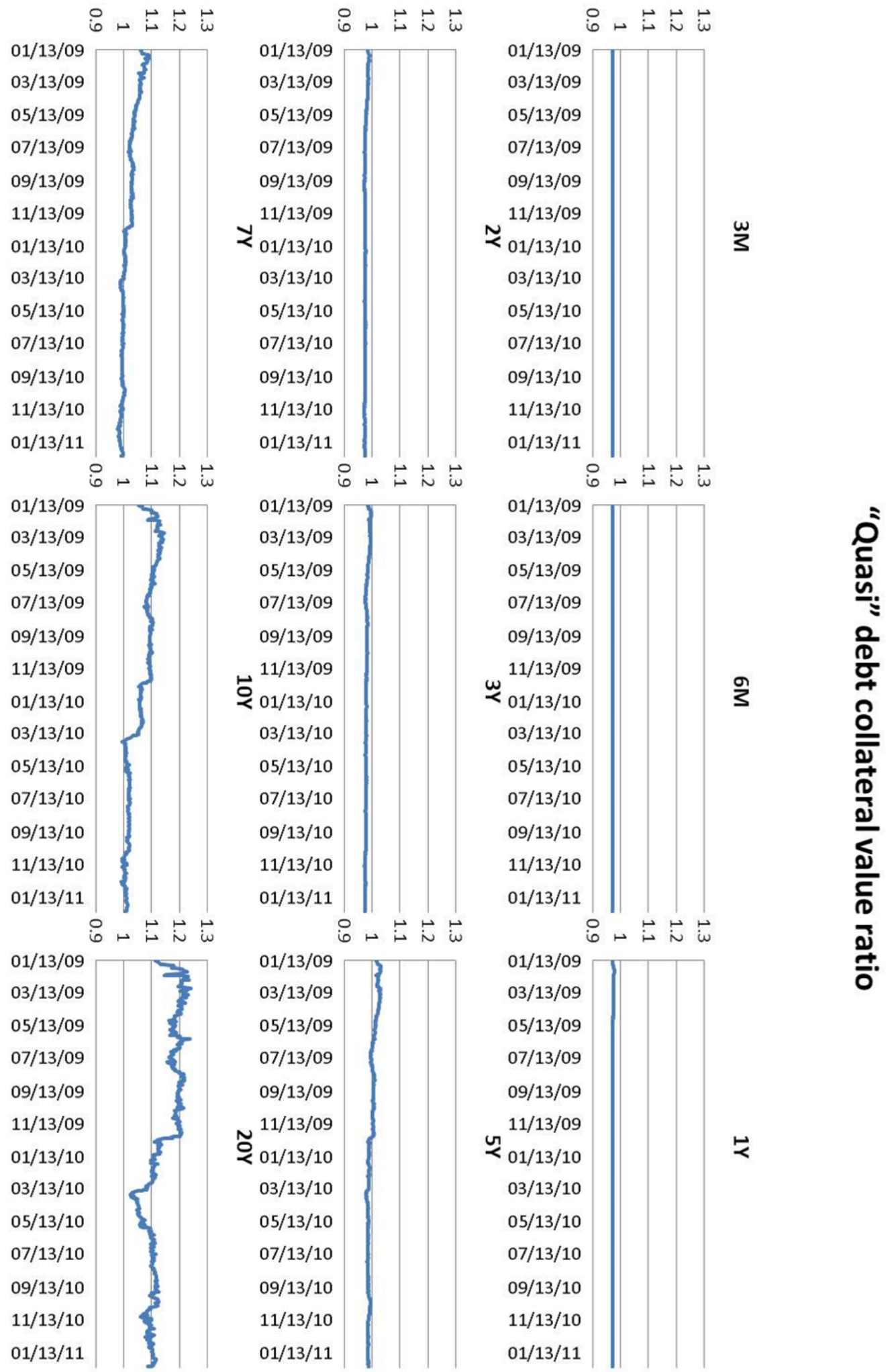

Figure 21 Quasi debt to collateral value ratios over the observation period 

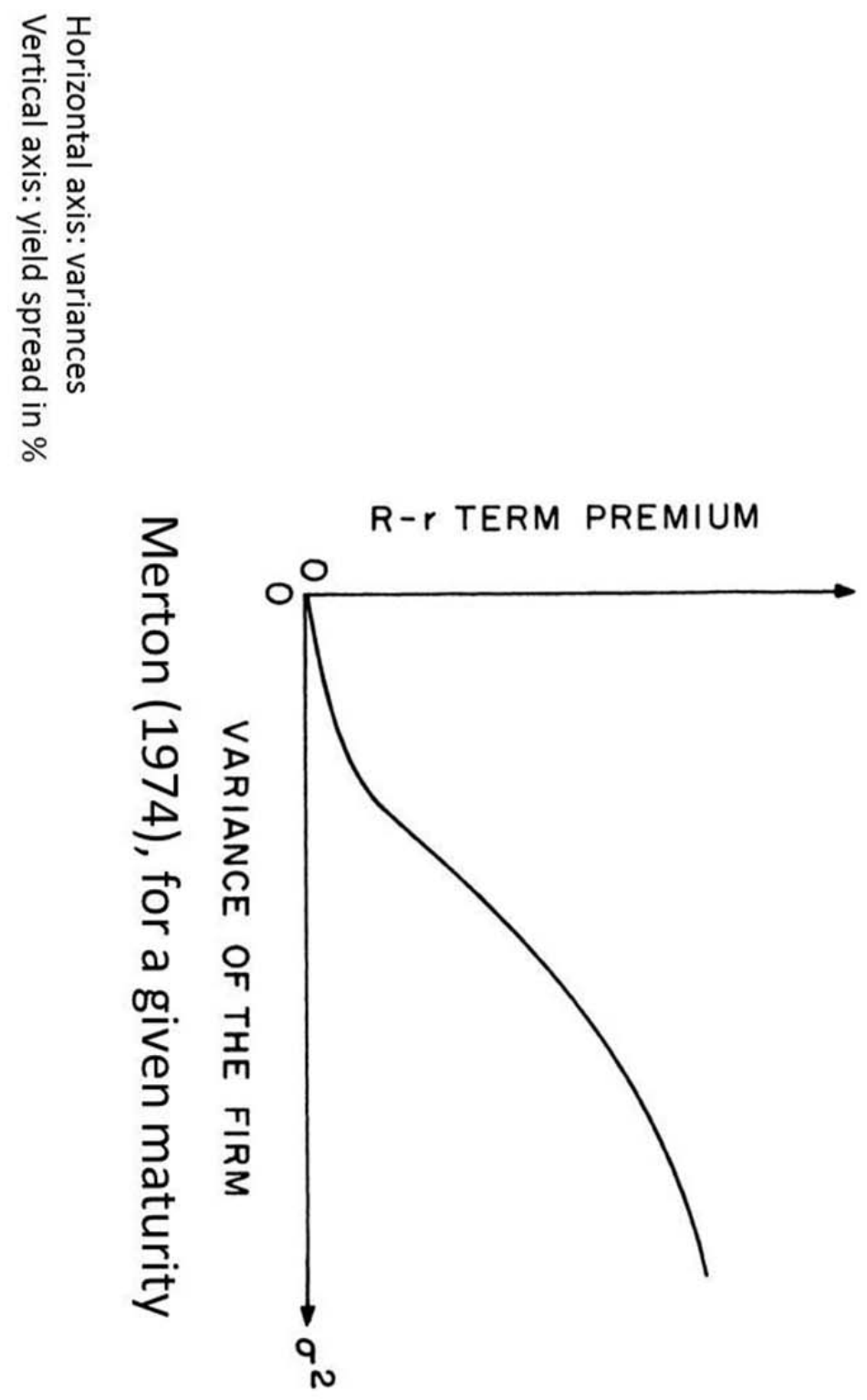

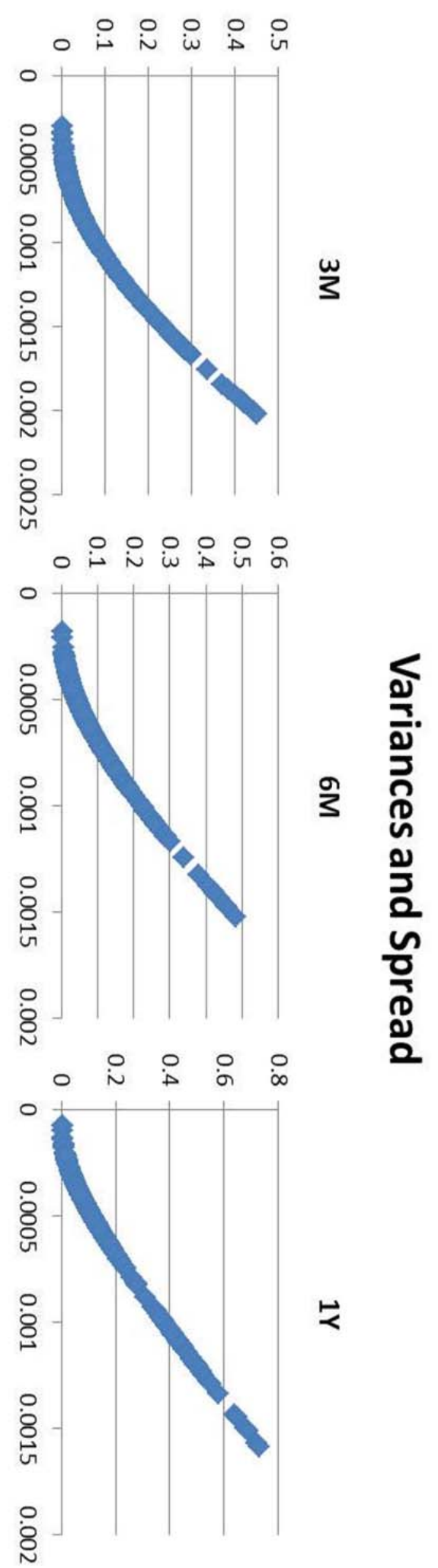

Figure 22 Comparison with Merton's result 


\subsection{Hypothetical Farm Credit System bond yield without GSE status}

It is shown in Table 4 that the biggest implied volatilities of all maturities never exceed 6.07\%, which represents the historical volatility of the farm land price. The $95 \%$ confidence interval of the historical land price volatility is shown in Table $\mathbf{9}$.

\begin{tabular}{ll}
\hline Actual historical land price volatility & $6.07 \%$ \\
\hline Standard Error & 0.000493 \\
upper 95\% limit & $6.16 \%$ \\
\hline lower 95\% limit & $5.97 \%$ \\
\hline
\end{tabular}

Table 9 95\% confidence interval of the historical land price volatility

As it shows, the maxima of the implied volatilities of all maturities are under the lower 95\% limit. Therefore, it can be claimed with high confidence that GSE status reduces the market perception for Farm Credit System's business risk and the Farm Credit System benefits from GSE status.

This section will answer the question which has been asked at the beginning of this thesis: How would the spread look like without GSE status?

Plugging the historical land price volatility (6.07\%) into the Black-Scholes Model, the put price on the bonds with all maturities which have no implicit government guarantee can be derived. Since the underlying risks are higher (the historical land price volatility is higher than the implied volatility), the put prices increase accordingly. Increasing put prices lead to higher yields. The results are presented in Table 10: 


\begin{tabular}{lccccccccc}
\hline & $\mathbf{3 M}$ & $\mathbf{6 M}$ & $\mathbf{1 Y}$ & $\mathbf{2 Y}$ & $\mathbf{3 Y}$ & $\mathbf{5 Y}$ & $\mathbf{7 Y}$ & $\mathbf{1 0 Y}$ & $\mathbf{2 0 Y}$ \\
\hline No GSE & 1.4618 & 2.0050 & 2.3919 & 2.8540 & 3.2389 & 3.9280 & 4.4898 & 4.9055 & 5.5036 \\
GSE & 0.2382 & 0.3190 & 0.5271 & 1.1181 & 1.5986 & 2.6068 & 3.3852 & 4.1196 & 4.8873 \\
Difference & 1.2236 & 1.6860 & 1.8648 & 1.7359 & 1.6403 & 1.3212 & 1.1045 & 0.7860 & 0.6163 \\
\hline
\end{tabular}

Table 10 Hypothetical yields without GSE status under constant volatility (6.07\%)

The first row presents the average hypothetical bond yields without GSE status over the whole observation period; the second row presents the average actual bonds yields of the Farm Credit System bonds with GSE status for comparison; the third row presents the difference between the hypothetical average spread and the actual average spread for a given maturity.

As shown in Table 10, the differences of spreads are particularly big for short-term bonds and much smaller for long-term bonds: the difference for the $1 \mathrm{Y}$ bond is as high as $186 \mathrm{bps}$, in contrast to that, the difference for the $20 \mathrm{Y}$ bond is only $62 \mathrm{bps}$. This result is surprising. While the hypothetical spreads for $10 \mathrm{Y}$ and $20 \mathrm{Y}$ seem to be reasonable, an average yield of $1.46 \%$ for $3 \mathrm{M}$ bond, an average yield of $2 \%$ for $6 \mathrm{M}$ bond and an average yield of $2.4 \%$ for $1 Y$ bond seem to be too high for the period from January 2009 to February 2011.

The main reason for this is because a constant volatility (which is equal to the historical volatility of the farm land price) for all maturities is assumed. As shown in chapter 5.4, average implied volatilities are not the same for all maturities and lower for bonds with shorter maturities and higher for bonds with longer maturities. 
Since the historical land price volatility (6.07\%) is based on the observations of over 60 years, it is reasonable to assume that it better represents the collateral value volatility of bonds with the longest maturity (20Y bond). For collateral value volatilities for the bonds with all other maturities, it is assumed that they change proportionally:

$$
\frac{\text { Implied volatility }(20 Y)}{\text { historical volatility }(20 Y)}=\frac{\text { Implied volatility }(T)}{\text { historical volatility }(T)}
$$

The volatilities for all other bonds are calculated with the following formula:

$$
\text { Historical volatility }(T)=\operatorname{Implied} \text { volatility }(T) \frac{\text { historical volatility }(20 Y)}{\operatorname{Implied} \text { volatility }(20 Y)}
$$

Plugging the adjusted historical volatilities into the Black-Scholes Model, the yields for different maturities can be derived. The results are presented in Table 11.

\begin{tabular}{lccccc}
\hline & GSE volatility & No GSE volatility & GSE yield & No GSE yield & Difference (bps) \\
\hline $\mathbf{3 M}$ & $2.65 \%$ & $3.86 \%$ & 0.2382 & 0.3744 & 13.62 \\
$\mathbf{6 M}$ & $2.32 \%$ & $3.37 \%$ & 0.3190 & 0.5193 & 20.02 \\
$\mathbf{1 Y}$ & $2.16 \%$ & $3.15 \%$ & 0.5271 & 0.7609 & 23.38 \\
\hline $\mathbf{2 Y}$ & $2.54 \%$ & $3.70 \%$ & 1.1181 & 1.5416 & 42.35 \\
$\mathbf{3 Y}$ & $2.56 \%$ & $3.73 \%$ & 1.5986 & 2.0269 & 42.83 \\
$\mathbf{5 Y}$ & $3.05 \%$ & $4.45 \%$ & 2.6068 & 3.1434 & 53.66 \\
$\mathbf{7 Y}$ & $3.37 \%$ & $4.91 \%$ & 3.3852 & 3.9641 & 57.89 \\
$\mathbf{1 0 Y}$ & $4.01 \%$ & $5.84 \%$ & 4.1196 & 4.8077 & 68.81 \\
$\mathbf{2 0 Y}$ & $4.17 \%$ & $6.07 \%$ & 4.8873 & 5.5036 & 61.63 \\
\hline
\end{tabular}

Table 11 Hypothetical yields without GSE status with adjusted volatilities

The first column of Table $\mathbf{1 1}$ lists all maturities. The actual average implied volatilities for all maturities are presented in the second column. The adjusted volatilities used to derive the hypothetical yields are shown in the third column. They are calculated based 
on the formula shown above. The fourth column presents the actual average yields of the Farm Credit System bonds with different maturities over the observation period. The hypothetical yields of the Farm Credit System bonds without GSE status can be found in the fifth column. They are calculated using the adjusted volatilities shown in the third column. The sixth column presents the differences of the yields without and with GSE status.

The results show that the average bond yield for a 3M FCS bond from January $13^{\text {th }} 2009$ to February $10^{\text {th }} 2011$ would be $0.3744 \%$ if the Farm Credit System had no GSE status, which is 13.62 bps higher than the actual bond yield. The difference between the hypothetical yield and the actual yield increases with increasing maturity and reaches its peak with $10 \mathrm{Y}$ bond. The difference between the hypothetical yield and the actual yield is 68.81 bps. The difference decreases slightly for $20 \mathrm{Y}$ bond. 


\subsection{Sensitivity analysis}

Merton (1974) shows that spread is influenced by volatility and quasi debt to collateral value ratio for a given maturity. In chapter 5.6, the historical land price volatility is used to represent the market perception for the collateral value volatility and the net collateral ratio is held constant at $103 \%$. The next two subsections will present the influences of various volatilities and various quasi debt to collateral value ratio (d-ratio) on the bond yields.

\subsubsection{Various volatilities}

As shown in chapter 3, the compositions of the assets are quite complex for the Farm Credit System and they are not all backed by the farm land. Therefore, 6.07\% might not be a good estimation for the collateral value volatility. Thus, a sensitivity analysis with different volatilities is done to show the influences of different volatilities on the bond yields.

\begin{tabular}{lcccccc}
\hline & GSE yield & $\mathbf{5 . 8 6 \%}$ & $\mathbf{5 . 9 3 \%}$ & $\mathbf{6 . 0 0 \%}$ & $\mathbf{6 . 0 7 \%}$ & $\mathbf{6 . 1 4 \%}$ \\
\hline $\mathbf{3 M}$ & 0.2382 & 1.3215 & 1.3679 & 1.4152 & 1.4618 & 1.5122 \\
$\mathbf{6 M}$ & 0.3190 & 1.8522 & 1.9030 & 1.9545 & 2.0050 & 2.0593 \\
$\mathbf{1 Y}$ & 0.5271 & 2.2444 & 2.2936 & 2.3433 & 2.3919 & 2.4440 \\
$\mathbf{2 Y}$ & 1.1181 & 2.7216 & 2.7659 & 2.8105 & 2.8540 & 2.9006 \\
$\mathbf{3 Y}$ & 1.5986 & 3.1172 & 3.1579 & 3.1989 & 3.2389 & 3.2816 \\
$\mathbf{5 Y}$ & 2.6068 & 3.8205 & 3.8565 & 3.8927 & 3.9280 & 3.9658 \\
$\mathbf{7 Y}$ & 3.3852 & 4.3914 & 4.4243 & 4.4575 & 4.4898 & 4.5243 \\
$\mathbf{1 0 Y}$ & 4.1196 & 4.8164 & 4.8463 & 4.8763 & 4.9055 & 4.9368 \\
$\mathbf{2 0 Y}$ & 4.8873 & 5.4308 & 5.4552 & 5.4798 & 5.5036 & 5.5291 \\
\hline
\end{tabular}

Table 12 Impact of various volatilities on yields 
The actual yields of bonds with GSE status can be found in the second column. The third to seventh columns present the hypothetical yields of bonds without GSE status. The yields in the third column are calculated under the assumption that the market perception for collateral value volatility is $5.86 \%$ for the FCS bonds with all maturities. The same interpretation applies to column four to column seven.

As shown in the above table, yields increase with collateral value volatility. It is consistent with Merton's theory: if the market expects the volatility of the underlying asset to be higher, it will require a higher compensation.

Therefore, if the Farm Credit System wants to maintain a low cost to raise capital after losing its GSE status, efficient risk management could help them to save cost. When it could make the market believe that its collateral value volatility is really low, they could issue bonds at a much lower yield.

\subsubsection{Various d-ratios}

It is shown in the previous section that d-ratio is primarily influenced by the net collateral ratio. The previous research is based on the assumption that the market expects the net collateral ratio to be equal to the minimum required net collateral ratio. If the Farm Credit System could increase its minimum net collateral ratio, its d-ratio will get smaller; bond yield will decrease if anything else remains the same. The results of the sensitivity analysis with different collateral ratios for a given collateral value volatility $6.07 \%$ are shown in Table 13. 


\begin{tabular}{lccccccccc}
\hline & GSE yield & $\mathbf{1 . 0 3}$ & $\mathbf{1 . 0 3 5}$ & $\mathbf{1 . 0 4}$ & $\mathbf{1 . 0 4 5}$ & $\mathbf{1 . 0 5}$ & $\mathbf{1 . 0 5 5}$ & $\mathbf{1 . 0 6}$ & $\mathbf{1 . 0 6 5}$ \\
\hline $\mathbf{3 M}$ & 0.2382 & 1.4618 & 1.0652 & 0.7846 & 0.5860 & 0.4460 & 0.3481 & 0.2802 & 0.2338 \\
\hline $\mathbf{6 M}$ & 0.3190 & 2.0050 & 1.6113 & 1.3078 & 1.0716 & 0.8867 & 0.7415 & 0.6274 & 0.5379 \\
\hline $\mathbf{1 Y}$ & 0.5271 & 2.3919 & 2.0522 & 1.7774 & 1.5522 & 1.3657 & 1.2103 & 1.0801 & 0.9706 \\
\hline $\mathbf{2 Y}$ & 1.1181 & 2.8540 & 2.5841 & 2.3593 & 2.1693 & 2.0070 & 1.8670 & 1.7455 & 1.6394 \\
\hline $\mathbf{3 Y}$ & 1.5986 & 3.2389 & 3.0087 & 2.8147 & 2.6488 & 2.5052 & 2.3798 & 2.2695 & 2.1718 \\
\hline $\mathbf{5 Y}$ & $\mathbf{2 . 6 0 6 8}$ & 3.9280 & 3.7431 & 3.5855 & 3.4492 & 3.3298 & 3.2243 & 3.1303 & 3.0461 \\
\hline $\mathbf{7 Y}$ & 3.3852 & 4.4898 & 4.3310 & 4.1950 & 4.0766 & 3.9724 & 3.8797 & 3.7966 & 3.7216 \\
\hline $\mathbf{1 0 Y}$ & 4.1196 & 4.9055 & 4.7713 & 4.6557 & 4.5545 & 4.4650 & 4.3850 & 4.3129 & 4.2475 \\
\hline $\mathbf{2 0 Y}$ & 4.8873 & 5.5036 & 5.4079 & 5.3248 & 5.1864 & 5.1864 & 5.1276 & 5.0743 & 5.0255 \\
\hline
\end{tabular}

Table 13 Impact of various d-ratios on yields

The second column shows the actual average yields of the Farm Credit System bonds with different maturities over the observation period. Column three to column ten present the hypothetical average bond yields of the Farm Credit System bonds without GSE status and with a constant collateral value volatility of $6.07 \%$ for all bonds. Column three shows the average bond yields if the minimum net collateral value is $103 \%$. The same interpretation applies to column four to column ten.

Bond yields decrease for all bonds with increasing net collateral ratio. This is because once the net collateral ratio increases, more assets are required for the same bond. It is less likely that the asset value falls under the barrier that the Farm Credit System decides to default on the bonds.

Moreover, despite yields decrease with increasing net collateral ratio the whole time for a given maturity, its marginal change is bigger at the beginning. Since volatilities are held constant at $6.07 \%$, according to Merton's (1974) theory, the only factor which influences the spread for a given maturity is the d-ratio. The d-ratios are lower for bonds with higher 
net collateral ratios. The average d-ratios for 3M bonds with different net collateral ratios are presented in Table 14.

\begin{tabular}{lcccccccc}
\hline $\begin{array}{l}\text { collateral } \\
\text { ratio }\end{array}$ & 1.03 & 1.035 & 1.04 & 1.045 & 1.05 & 1.055 & 1.06 & 1.065 \\
\hline 3M d-ratio & 0.9730 & 0.9674 & 0.9620 & 0.9569 & 0.9521 & 0.9473 & 0.9427 & 0.9382 \\
3M yield & 1.4618 & 1.0652 & 0.7846 & 0.5860 & 0.4460 & 0.3481 & 0.2802 & 0.2338 \\
\hline
\end{tabular}

Table 14 Average d-ratios for 3M bonds with different net collateral ratios

By comparing the 3M yields with different d-ratios with Merton's curve, these two curves have the same shape. It is shown in Figure 25. 3M yields with different d-ratios are presented on the LHS of Figure 25. Merton's original graph can be found on the LHS of Figure 25.

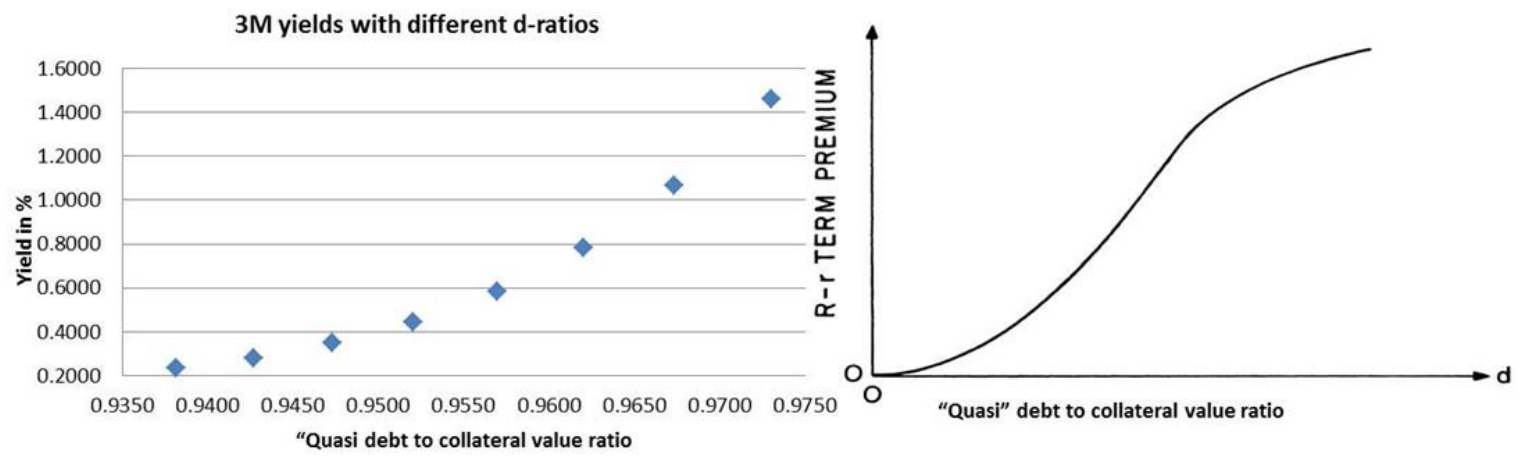

Figure 25 Impact of d-ratios on yield and comparison with Merton's finding (Source: Merton (1974))

It is to notice that Merton uses the y-axis to represent spreads. In contrast to that, the yaxis of the graph on the LHS represents yields. It does not matter because 3M risk-free interest rates are the same for all bonds, even though the d-ratios vary. Therefore, the 3M spread curve is a parallel shift of the $3 \mathrm{M}$ yield curve. 
By comparing the hypothetical yields with the actual yields under GSE status, it shows that the Farm Credit System could efficiently reduce its cost of capital as long as they could increase its minimum net collateral ratio. The Farm Credit System could have issued 3M bonds at an average yield which is even lower than the actual 3M average yield with GSE status if it had not GSE status but a net collateral ratio of $106 \%$. 


\section{Conclusion and extension suggestions}

This thesis tries to quantify the impact of GSE status on the yields of the Farm Credit System bonds. It presents a framework to answer the question how the bond yield would look like for the Farm Credit System without GSE status.

In order to do so, the daily Farm Credit System bond yields for different maturities from January $13^{\text {th }} 2009$ to February $10^{\text {th }} 2011$ are used to identify the factors which influence spread. Merton (1974) shows that the spread of a bond is influenced by the volatility, the maturity and the quasi debt to collateral value ratio (d-ratio). The factors influencing spreads of the FCS bonds are consistent with Merton’s theory.

Moreover, this thesis presents the hypothetical Farm Credit System bond yields without GSE status. It shows that the bond yields would have been higher over the observation period. It would have been especially high for long-term bonds and the difference could have been as big as 69 basis points.

This thesis also shows that the Farm Credit System could reduce its capital cost by efficient risk management and a higher net collateral ratio.

Due to data limitations, there are still many important issues which are not covered by this paper. The following paragraphs present some extension suggestions.

As for now, the Farm Credit System bonds enjoy the same tax status as the treasury bonds. They are exempt from the local and state taxes. Federal taxes, however, are still due on the earned interest. If the Farm Credit System lost its GSE status, it might also 
lose its favorable tax treatments and the cost of capital will increase. This research does not consider the influence of tax treatment on the yield of the Farm Credit System bonds. A wide range of research has been done to investigate the tax effect on bond yield: Cowan and Pertrine (2002), Elton and Green (1998) and Green and Odegaard (1997) etc.

One other interesting extension of this paper would be the explanation for the negative spreads of the short-term bonds. As shown in chapter 4, there were times when spreads for short-term bonds were negative. This would mean that the market would expect the risk of the short-term Farm Credit System bonds to be even lower than the risk-free treasury notes, which is not possible. Moreover, as shown in chapter 4, bonds with 3M, $6 \mathrm{M}$ and $1 \mathrm{Y}$ maturities had negative spreads in different periods. Since negative spreads for different maturities occurred at different times, a single policy change may not be enough to explain it. The explanation offered in this thesis is insufficient to explain this phenomenon; further research is needed to explore this problem.

Furthermore, due to data limitations, this paper does not consider the influences of special bond features on spread. According to Jacoby (2002) and Duffee (1998), callability has significant influences on the spread of a given bond. Specifically, the conditional probability of a call, the call price set in the call provision, the call-protected period etc. will all have impacts on the spread of a given bond. Since the Federal Farm Credit Bank Curve does not distinguish between callable and non-callable bonds, it is impossible to quantify the impacts of call features on spread based on this data set.

Last but not least, it is assumed in this research that GSE status does not depend on maturity. In other words, it is assumed that one would expect that the impact of GSE 
status to remain the same regardless of maturity. However, it is not always the case in reality. Especially now when the Farm Credit System is in danger of losing its GSE status, some people may expect the Farm Credit System to lose its GSE status in the future. This expectation will certainly impact the expected payments for long-term bonds, but to less extent the expected payments for short-term bonds. This impact is not captured by this research. Further research could be done to explore the impact of maturity on GSE status by making the impact of GSE status as a function of maturity. 


\section{References}

Black, F. and Scholes M. (1973) The Pricing of Options and Corporate Liabilities.

Journal of Political Economy, 81 (May-June): 637-54.

Cowan, M and Pertrine, R (2002) Taxes and the Pricing of Government Sponsored Entity

Bonds, Working paper, University of Alabama at Birmingham

Duffee, G. (1998) The Relation between Treasury Yields and Corporate Bond Yield Spreads, Journal of Finance, 54, 2225-2241.

Elton, E. and Green, C. (1998) Tax and liquidity effects in pricing government bonds, Journal of Finance 53, 1533-1562.

Freshwater (1998) Can Continuation of GSE Status for the Farm Credit System Justified, Journal of Public Budgeting Accounting and Financial Management Vol. 11, 35-53

Gray,D., Merton,R.C and Bodie, Z (2007) Contingent Claims Approach to Measuring and Managing Sovereign Credit Risk, Journal of Investment Management Vol. 5(4), 1-24.

Green, R. and Odegaard, B. (1997) Are there tax effects in the relative pricing of U.S. government bonds, Journal of Finance 52, 609-633

Jacoby, G. (2002) On estimating the relation between corporate bond yield spreads and Treasury yields, Working paper, University of Manitoba. 
Lee, W.F., and G.D. Irwin (1996) Restructuring the Farm Credit System: A Progress Report, Agricultural Finance Review, 56, 1-21.

Lins, D. and Barry, P (1984) Agency Status for the Cooperative Farm Credit System, American Journal of Agricultural Economics 66(5), 601-606

Merton, R. C. (1977) An Analytic Derivation of the Cost of Deposit Insurance and Loan Guarantees, Journal of Banking and Finance 1, 3-11Journal of Banking and Finance 1 (1977) 3

Merton, R. C. (1974) On the Pricing of Corporate Debt: The Risk Structure of Interest Rates, Journal of Finance 29 (May), 449-70.

Tauer, L. and A. Weersink (1987) Optimal Equity Recovery for a Cooperative Financial Institution, In A Changing Environment: Macro, Market, Policy and Management Issues Proceedings, Department of Agribusiness Economics, Southern Illinois University 